Harald Lang

Florian Morath

\title{
A Glance into the Tunnel: Experimental Evidence on Income Comparisons under Uncertainty
}

Max Planck Institute for Tax Law and Public Finance

Working Paper 2015 - 13

November 2015

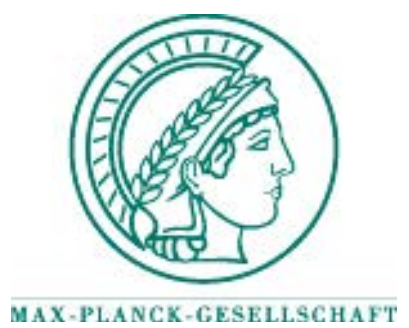

Max Planck Institute for

Tax Law and Public Finance

Department of Business and Tax Law

Department of Public Economics

http:/ / www.tax.mpg.de 
Working papers of the Max Planck Institute for Tax Law and Public Finance Research Paper Series serve to disseminate the research results of work in progress prior to publication to encourage the exchange of ideas and academic debate. Inclusion of a paper in the Research Paper Series does not constitute publication and should not limit publication in any other venue. The preprints published by the Max Planck Institute for Tax Law and Public Finance represent the views of the respective author(s) and not of the Institute as a whole. Copyright remains with the author(s).

Max Planck Institute for Tax Law and Public Finance

Marstallplatz 1

D-80539 Munich

Tel: $\quad+498924246-0$

Fax: $\quad+498924246-501$

E-mail:ssrn@tax.mpg.de

http://www.tax.mpg.de 


\title{
A glance into the tunnel: Experimental evidence on income comparisons under uncertainty
}

\author{
Harald Lang* Florian Morath ${ }^{\dagger}$
}

January 27, 2016

\begin{abstract}
Learning that others earn more may reduce individual well-being but it can also be informative about the own income prospects. In an environment of uncertainty over the own income, this paper provides experimental evidence on direct income-comparison effects on well-being and informational effects from observing signals about others' income prospects. We find that individual beliefs about the own income are adjusted downwards when observing that others are likely to earn less, but do not significantly adjust when observing that others are likely to earn more. Individual satisfaction decreases when others are likely to earn more but does not change significantly when others are likely to earn less. Overall, informational effects countervail direct incomecomparison effects if and only if the uncertainty over the own income is sufficiently strong.

JEL codes: C91, D31, D63, D84
\end{abstract}

Keywords: Tunnel effect, relative income, expectations, belief formation, subjective well-being, experiment

*Max Planck Institute for Tax Law and Public Finance. E-mail: harald.lang@tax.mpg.de

${ }^{\dagger}$ Max Planck Institute for Tax Law and Public Finance. E-mail: florian.morath@tax.mpg.de 


\section{Introduction}

When individuals care about relative standing, observing changes in the income of others will affect their utility. At the same time, however, individuals may make inferences about their own future income prospects from observing that others' earnings increase or decrease. If the positive experiences of others cause an upward adjustment of the beliefs about the own income prospects, the informational value of observing the advances of others can countervail the direct effect on subjective well-being caused by relative-standing concerns and affect the individual tolerance for income inequality. Using data from a controlled laboratory experiment we separate the direct comparison effect from the purely informational effect of learning about others' income and examine their importance for subjective well-being. Overall, our findings suggest that individuals are more reactive to "bad news" than to "good news," both in how they adjust their expectations of own income prospects and in how subjective well-being is affected. In environments with sufficiently strong uncertainty over the own income prospects, informational effects on the expectations of own future income may offset direct income-comparison effects caused by concerns for relative standing.

The information-driven effect of increases in well-being following the advances of others has received less attention in the literature and was first discussed in a seminal paper by Hirschman (1973). Hirschman claims that the positive informational value of observing that the earnings of your peers have increased may even outweigh the negative effect driven by relative-standing concerns, illustrating such a situation with a tunnel anecdote: Suppose you are in a tunnel and you are stuck in a traffic jam. As far as you can see, nothing is moving and you are feeling dejected. All of a sudden, the cars in the lane next to you start moving. Even though you are still stuck in your lane, you may feel relieved as the traffic jam seems to be breaking. While your relative position is deteriorating, the positive signal about the possibly dissolving traffic jam leaves you, altogether, more satisfied than you were before.

Hirschman (1973) concludes that information-driven effects can be important determinants for attitudes toward inequality and redistribution. When future (lifetime) income is uncertain, learning about others' experiences may lead to individuals adjusting their perceptions of income mobility within their society, thereby affecting attitudes toward redistribution. Our experimental results not only provide support in favor of the importance of the experiences of peers, it also hints at a potential asymmetry in the process of how individuals update their beliefs about the mobility process. ${ }^{1}$ We find that a higher weight is given to

\footnotetext{
${ }^{1}$ Individual perceptions of social mobility can be influenced by many factors such as past experience, parental background or the social environment and need not necessarily mirror the actual mobility rates; see, for instance, Alesina et al. (2004) on differences in beliefs about social mobility as an explanation for differences in views on inequality between the United States and Europe.
} 
signals that indicate the potential of downward mobility. This asymmetry may directly affect reactions of individual well-being to inequality and the demand for redistributive policies; more broadly, individual perceptions of social mobility (rather than actual mobility) may shape general political attitudes and social cohesion.

Some empirical approaches have been undertaken to study Hirschman's "tunnel effect," usually relying on survey data. Using data for Russia, Ravallion and Lokshin (2000) provide evidence that individuals who expect their economic situation to improve show a weaker support for redistribution. Studies by Senik (2004, 2008) find evidence that personal life satisfaction may react positively to an increase in the income of a reference group. Clark et al. (2009) match Danish employer-employee data with survey data and find supportive evidence of a positive correlation between job satisfaction and the income of colleagues. Whereas empirical evidence on the joint occurrence of comparison considerations and informational effects from the field is a natural and important starting point, studies based on field data generally suffer from eminent problems. First, the measurement of the relevant variables can be defective in several ways. For instance, income runs at the risk of being under-declared, measures of individuals' expectations of future income prospects are usually crude in survey data and income can be endogenous to satisfaction. ${ }^{2}$ Furthermore, it is difficult to identify the income of a relevant reference group and to confirm to what extent (or whether at all) the reference group's income is observable. ${ }^{3}$ Many problems in the field can be addressed in the laboratory. The controlled environment allows us to observe the income of participants and of a clearly defined reference group. We can directly measure individual satisfaction levels and the beliefs about their income prospects, controlling for the information received on the income-generating process. This more detailed and causal identification enables us to directly analyze adjustments in beliefs as a consequence of additional information, rather than focusing on changes in satisfaction that are supposed to be caused by changes in beliefs. Thus, we can separate the income-comparison and belief-based effects resulting in Hirschman's (1973) "tunnel effect."

In the experiment we endow participants with income in the form of a "portfolio." The portfolio value follows a stochastic process and the final portfolio value determines a subject's income. Hence, subjects are ex ante uncertain of their income and the income of others but receive additional information about the final portfolio value (their income) in the course of the experiment. In regular time intervals we measure changes in the subject's beliefs about their final income and in individual well-being (the self-reported satisfaction

\footnotetext{
${ }^{2}$ For instance, satisfied people might be extraverted and possibly more successful in their job.

${ }^{3}$ Some of the problems are addressed in one way another in the studies cited above. Nevertheless, it remains generally true that a completely clean identification is inaccessible in the field.
} 
with their portfolio). To isolate purely belief-based effects of receiving additional signals of the underlying income-generating process ("information effects") we compare the beliefs of a control group that only observes their own portfolio to a treatment group (treatment "P2-INFO") that observes not only the exact same own portfolio but, in addition, another portfolio which may have informational value for the own income but is not assigned to any other participant of the experiment. To measure direct "income-comparison effects" we use observations from this P2-INFO treatment as a control group and compare the self-reported satisfaction levels to another treatment group (treatment "P2-INCOME") in which subjects are matched in groups of two and observe each other's income-generating process. Thus, holding constant the information that subjects may use to infer their own income prospects (i.e., portfolio values) we provide precise information on another subject's likely income and estimate its effect on self-reported satisfaction. The main experimental treatments keep the informativeness of additional signals uncertain by not providing precise information on the income-generating process; instead, subjects are shown a distribution of possible income realizations. In additional control treatments we vary the subjects' priors by keeping them completely uncertain of the distribution of final incomes.

We find evidence both for "information effects" on the beliefs about the own income and for direct "income-comparison effects." Both types of effects turn out to be asymmetric. On the one hand, expectations about the own income only react significantly when participants observe additional portfolios with lower values, in which case subjects lower their beliefs. On the other hand, relative-standing concerns most strongly affect satisfaction in situations where individuals observe that others are likely to earn more, in which case subjects report lower satisfaction levels. Belief-based effects and income-comparison effects offset each other in how they affect well-being when the uncertainty of individual incomes is substantial and, hence, information-driven effects are important; in situations of low uncertainty the incomecomparison effects of learning of the income prospects of others prevail.

The discussion on relative-income comparisons dates back to Veblen (1899) and Duesenberry (1949) and there is a vast literature on the importance of relative-income considerations for economic outcomes. ${ }^{4}$ More specifically, a substantial amount of evidence documents a negative relationship between subjective well-being and the income of a defined reference group (see, e.g., Van de Stadt et al. 1985; Clark and Oswald 1996; McBride 2001; Ferrer-i-Carbonell 2005; Luttmer 2005; Senik 2009; Clark and Senik 2010). Ferrer-i-Carbonell and Ramos (2014) survey the literature on the relation between inequality and subjective

\footnotetext{
${ }^{4}$ For early contributions see, for instance, Leibenstein (1950), Easterlin (1974, 1995), Boskin and Sheshinski (1978), Frank (1984, 1985), Konrad (1992), and Konrad and Lommerud (1993). Clark et al. (2008) review the literature on income comparisons and well-being.
} 
well-being. Consistent with the ideas of Duesenberry (1949), studies by Ferrer-i-Carbonell (2005), Senik (2009), and Clark and Senik (2010) find that the relative-income considerations are asymmetric, meaning that people compare mostly upwards. We contribute to this empirical literature in two respects. First, we focus on income-comparison considerations under uncertainty, controlling for informational effects that become important in an uncertain environment. Second, we provide experimental evidence in a novel and, as we believe, particularly simple setting, in which we show that seemingly minor institutional changes (individuals learn of the income prospects of another participant, instead of only observing a second portfolio which is not payoff-relevant for any other participant) in an otherwise exactly similar situation induces significant income-comparison effects.

Under uncertain future and, hence, lifetime earnings income comparisons directly involve the perception of social mobility. Bénabou and Ok (2001) rationalize and provide conditions for the "prospect of upward mobility" (POUM) hypothesis that a majority of individuals may expect to become richer than average in the future. ${ }^{5}$ Their work on the POUM hypothesis, explaining the lack of support for high levels of redistributive taxation, assumes that individuals know the income-generating mobility process. Our experiment investigates expectations of future income in an environment where the income-generating process and, hence, the informativeness of learning of others' income prospects for the own future income is uncertain. We believe this is particularly interesting because outside the laboratory people might observe income signals about the income of others; however, the underlying correlation between future incomes is in most cases uncertain. In this respect, our paper also relates to Piketty (1995) who takes into account that individuals may exhibit heterogeneous beliefs about upward mobility and focuses on learning about the relative importance of individual effort as compared to parental background. ${ }^{6}$ Our results for the asymmetry of how subjects take into account additional information may be interpreted as subjects being mostly concerned about downward mobility.

Finally, our paper relates to the literature on expectations formation (e.g., Schmalensee 1976; Dwyer et al. 1993; Hey 1994; Hommes 2011; Rötheli 2011; Beshears et al. 2013).

\footnotetext{
${ }^{5}$ This and further explanations for why in democracies the low-income majority does not implement high levels of redistribution are discussed by Putterman (1997); see also Fong (2001) on beliefs about distributive justice and Luttmer and Singhal (2011) on the role of cultural background. For empirical studies on the relation between perceptions of social mobility and preferences for redistribution see Ravallion and Lokshin (2000), Corneo and Grüner (2002), Alesina and La Ferrara (2005), Guillaud (2013), and Cojocaru (2014). Checchi and Filippin (2004), Krawczyk (2010), Konrad and Morath (2013), and Durante et al. (2014) experimentally investigate preferences for redistributive taxation under different income mobility regimes.

${ }^{6}$ Our setting takes individual incomes as fully exogenous and predetermined and abstracts from questions of the sources of inequality, which have been extensively discussed in the literature on redistributive preferences. For seminal contributions on the role of beliefs about the sources of inequality for redistributive outcomes see Alesina and Angeletos (2005) and Bénabou and Tirole (2006).
} 
However, we are not primarily interested in the expectations individuals form about a time series (in our setting, their income prospects). Our experiment focuses on how subjects adjust their expectations when they observe another individual's income prospects. We deliberately refrain from inducing the individuals to believe in a particular correlation structure but investigate how individual beliefs react to signals about a second mobility process, in situations where the underlying income-generating process is unknown.

\section{Framework}

\subsection{Information and income-comparison concerns}

Consider a model with two individuals. Individual $i \in\{1,2\}$ realizes future income denoted by $y_{i} \in \mathbb{R}_{+}$. We assume that individual $i$ cares about relative standing and, hence, cares about both his own income and the income of individual $j \neq i$. The preferences of $i$ are described by the utility function

$$
u_{i}\left(y_{i}, y_{j}\right)=y_{i}-\lambda_{i} y_{j}
$$

where the parameter $\lambda_{i} \geq 0$ reflects $i$ 's concerns about relative standing.

Future income of the individuals is uncertain. Individual $i$ observes a signal $s_{i} \in \mathbb{R}$ on the own future income $y_{i}$ as well as a signal $s_{j} \in \mathbb{R}$ on the other individual's future income $y_{j}$. Denote by $E_{i}\left(y_{k}\right)$ individual $i$ 's expectation about $y_{k}$. Then, $i$ 's expected utility conditional on the signals $\left(s_{i}, s_{j}\right)$ is equal to

$$
E_{i}\left[u_{i}\left(y_{i}, y_{j}\right) \mid\left(s_{i}, s_{j}\right)\right]=E_{i}\left[y_{i} \mid\left(s_{i}, s_{j}\right)\right]-\lambda_{i} E_{i}\left[y_{j} \mid\left(s_{i}, s_{j}\right)\right] .
$$

We assume $i$ 's beliefs about $y_{k}$ to be strictly increasing in the signal $s_{k}$, that is,

$$
\frac{\partial E_{i}\left[y_{k} \mid\left(s_{1}, s_{2}\right)\right]}{\partial s_{k}}>0, k=1,2 .
$$

Moreover, $i$ 's beliefs about the own income $y_{i}$ may also depend on what $i$ observes about $j$ 's income, that is, on $s_{j}$. (Similarly, $i$ 's expectation about $y_{j}$ may depend on the signal $s_{i}$ about the own income.) Thus, changes in $s_{j}$ affect $i$ 's expected utility through changes in his expectations of his own and the other individual's income:

$$
\frac{\partial E_{i}\left[u_{i}\left(y_{i}, y_{j}\right) \mid\left(s_{i}, s_{j}\right)\right]}{\partial s_{j}}=\frac{\partial E_{i}\left[y_{i} \mid\left(s_{i}, s_{j}\right)\right]}{\partial s_{j}}-\lambda_{i} \frac{\partial E_{i}\left[y_{j} \mid\left(s_{i}, s_{j}\right)\right]}{\partial s_{j}} .
$$


The second term of the derivative in (2) is negative if $\lambda_{i}>0$ and (1) holds. A higher signal $s_{j}$ about $j$ 's income has a direct negative effect on $i$ 's expected utility whenever $i$ has concerns about relative standing: a higher expected income of $j$ makes $i$ worse off in relative terms. We call this direct effect an "income-comparison effect." The first term in (2) depends on how $i$ interprets information on $j$ 's income regarding his own future income. If $i$ expects own future income $y_{i}$ and the other individual's future income $y_{j}$ to be positively correlated then the first term of the derivative in (2) may be positive, that is,

$$
\frac{\partial E_{i}\left[y_{i} \mid\left(s_{i}, s_{j}\right)\right]}{\partial s_{j}}>0 .
$$

In this case, there is an "information effect" on own expected income that countervails the direct negative effect on $E_{i}\left(u_{i}\right)$ from observing a higher signal $s_{j}$. Positive signals about the income of others can increase $i$ 's expected utility if these signals convey positive information of the own income. If (3) holds, the total effect in (2) can be positive or negative, depending on whether the "information effect" or the "income-comparison effect" dominates. The experimental treatments described next isolate the two effects and test them separately.

\subsection{Experimental treatments}

The experiment consists of three treatments which are implemented in a between-subjects design. In each of the treatments, participant $i$ is assigned a "portfolio" $P_{i}$ whose value follows a stochastic process. Participant $i$ observes the value $y_{i}(t) \in \mathbb{R}$ of portfolio $P_{i}$ at points in time $t=0,1,2, \ldots, T$. The value $y_{i}(0)$ is identical for all portfolios/participants; the final value $y_{i}(T)$ is ex ante uncertain and determines $i$ 's income in the experiment. Hence, the values $y_{i}(t)$ at $t<T$ represent signals about $i$ 's income.

Portfolios are generated by a random walk with drift, with $y_{i}(0)=300$ and

$$
y_{i}(t)=y_{i}(t-1)+\alpha_{i}+\beta \varepsilon_{i}(t)
$$

The final period is $T=100$ and the drift parameter $\alpha_{i}$ is randomly drawn (with equal probabilities) from the set $\{-1.5,0,1.5\}$ in order to obtain different types of portfolios (lowvalue, medium-value, and high-value portfolios). ${ }^{7}$ The subjects observe the dynamic process of the portfolio on the screen in a diagram (with the time dimension on the horizontal axis and the portfolio value on the vertical axis; for a screenshot see Figure A.2 in the appendix).

\footnotetext{
${ }^{7}$ The shocks $\varepsilon_{i}(t)$ are independent draws from a standard normal distribution, and the parameter $\beta$ is a constant to scale the shock $\varepsilon_{i}(t)$ (we set $\beta=10$ ).
} 
The participants are not informed of the exact stochastic process that governs the portfolios. Instead, the experiment's instructions contain a graph which shows a large number of portfolios generated by the stochastic process in (4) (compare Appendix C). This ensures that subjects have a comparable prior of the income-generating process and the probability distribution of final incomes, and it reduces the within-treatment variation without imposing too much structure or exploiting differences in computational skills.

The participants' task is to repeatedly answer questions on their beliefs about the final portfolio value $y_{i}(T)$ and on their satisfaction with the assigned portfolio. ${ }^{8}$ The first main task is to give an estimate of the final value $y_{i}(T)$ of the income-generating process; this task is incentivized. The second main question asks directly for an individual's satisfaction with the assigned portfolio, on a scale from 0 (highly unsatisfied) to 10 (very satisfied). This question serves as a self-reported measure of utility. ${ }^{9}$

As a plausibility check for the self-reported satisfaction we also include a control question in which subjects are given the option to receive as their earnings the final value of an alternative portfolio to be randomly generated by the same process. Subjects should be more likely to choose this option if they are less satisfied with their current portfolio; we can test whether their choice is correlated with the self-reported satisfaction. ${ }^{10}$

Treatment BASE In the baseline treatment, each subject observes only the value $y_{i}(t)$ of the own portfolio $P_{i}$ at points in time $t=0,1, \ldots, T$. The BASE treatment is used to establish a benchmark for the individuals' beliefs about the own final portfolio value (i.e., income) in the absence of information about other individuals' income.

Treatment P2-INFO In the P2-InFo treatment, subject $i$ observes the value $y_{i}(t)$ of the own portfolio $P_{i}$ and, in addition, the value $y_{j}(t)$ of a second portfolio $P_{j}$ at points in time $t=0,1, \ldots, T$. This second portfolio has no payoff relevance for any other individual;

\footnotetext{
${ }^{8}$ For the exact description of the task see the experimental instructions in Appendix C.

${ }^{9}$ Although this might be a bit imprecise we use the terms satisfaction, subjective well-being, and utility interchangeably. For our experiment we rely on the general conclusion in the literature that self-reported satisfaction or subjective well-being is a meaningful measure (for a recent survey see Weimann et al. 2015). For a discussion on action-revealed preferences and satisfaction judgments see Frey and Stutzer (2002).

${ }^{10} \mathrm{We}$ include this control question in two variants: In approximately half of the sessions of each treatment, if the option to have the individual earnings determined by another randomly generated portfolio is chosen, the subject is assigned and shown the new portfolio at the end of the experiment. In the other half of the sessions, subjects are only asked "hypothetically" whether they would prefer to be assigned another portfolio. In both cases, subjects answer all questions on beliefs and satisfaction with respect to the originally assigned portfolio $P_{i}$ (even if they prefer the value of another portfolio as their final earnings). We use these two variants to control for possible interference of the control question (the possibility to receive the final value of another portfolio) with the self-reported measure of satisfaction. Note that these two different types of sessions are very similar in terms of results obtained.
} 
it is common knowledge that it is not assigned to any other participant of the experiment. Using the BASE treatment as a counterfactual, this intermediate treatment P2-INFO isolates the effect of additional information $\left(y_{j}(t)\right)$ on an individual's beliefs about the own income ("information effect"), in a situation in which this information is not directly informative of the income of another participant of the experiment.

Treatment P2-INCOME The P2-InCome treatment differs from the P2-Info treatment only in that the second portfolio $P_{j}$ is assigned to another participant of the experiment (which is common knowledge). More precisely, two participants $i$ and $j$ of the experiment are randomly matched and both observe the values $y_{i}(t)$ and $y_{j}(t)$ at points in time $t=0,1, \ldots, T$ (but not the other participant's choices). Using treatment P2-INFO as a counterfactual, the P2-INCOME treatment isolates the effect of observing the income prospects of others on own satisfaction ("income-comparison effect"). Since we use the same sets of portfolios across treatments (for more details see below), the comparison of P2-INCOME to P2-INFO controls for any informational effect that observing portfolio $j$ may have on $i$ 's beliefs about the own income (and, hence, on satisfaction with the own portfolio). In other words, we separate the "income-comparison effect" from the "information effect" derived in Section 2.1. ${ }^{11}$

\subsection{Experimental procedures}

Each of the three treatments BASE, P2-InFo, and P2-InCOME consists of 10 structurally identical but independent rounds indexed by $r \in\{1, \ldots, 10\}$. Hence, participant $i$ observes a sequence of 10 own portfolios; in the treatments P2-INFO and P2-INCOME $i$ also observes 10 additional portfolios in total. In the P2-INCOME treatment, the participants are randomly matched in groups of two in each of the 10 rounds. ${ }^{12}$

To allow for perfect counterfactuals we assign the portfolios such that a subset of players across all treatments observes an identical sequence of portfolios (own portfolios and potentially co-players' portfolios) in rounds $r=1, \ldots, 10 .{ }^{13}$ Therefore, the treatment comparisons

\footnotetext{
${ }^{11}$ By making others' income prospects more salient the "income-comparison effect" is also based on additional information. We refer to "information effect" in the context of the effects on beliefs about the own income; the "income-comparison effect" relates to the channel which works through specific information about another participant's expected income and, hence, potential income inequality.

${ }^{12}$ The participants do not interact or observe other participants' decisions. We implement random rematching to assure that income comparison refers to the current round and to avoid that subjects take into account information on the assigned co-player's earnings in previous rounds.

${ }^{13}$ We randomly selected 20 portfolios to be used in all treatments (see Appendix B.4), which are assigned such that subsamples of participants in each treatment observe the exact same 10 "own" portfolios over the 10 rounds. Moreover, in P2-INFo and P2-InCOME all participants of a subsample observe the exact same 10 additional portfolios. We generated six random sequences in which these portfolios are shown to the subjects; subjects are then randomly assigned to one of these sequences. When selecting the 20 portfolios
} 
control for portfolio history effects, that is, for information on portfolio values in previous rounds and in a given round (up to $t$ ).

In each round $r$, participant $i$ answers the questions on satisfaction and beliefs about $y_{i, r}(T)$ at points in time $t \in\{T / 5,2 T / 5,3 T / 5,4 T / 5\}$ where at later points $t$ individuals have observed more signals and uncertainty over $y_{i, r}(T)$ is reduced. At each point in time $t$, the subjects can give their answers on beliefs and satisfaction independently of their previous answers. At the end of the experiment the computer randomly selects one round $\hat{r}$ out of the 10 rounds; then the computer randomly selects one point in time $\hat{t}$ of this round at which the questions have been answered. The participants' choices at this selected point in time $\hat{t}$ determine their earnings in the experiment as follows: First, subjects receive a payment for their estimate $\tilde{y}_{i, \hat{r}}(\hat{t})$ of their final portfolio value in round $\hat{r}$; this payment increases in the precision of the estimate. ${ }^{14}$ Second, each subject receives the final value $y_{i, \hat{r}}(T)$ (in experimental currency) of the portfolio assigned in the selected round. ${ }^{15}$ The payment received in experimental currency units (ECU) is converted to Euros at a rate of $25 \mathrm{ECU}=1$ Euro. Third, subjects receive a lump-sum payment of 2 Euros for reporting their satisfaction and a show-up fee of 4 Euros.

The experiment was programmed and conducted with the experiment software z-Tree (Fischbacher 2007) and was run at the University of Munich. Each treatment consisted of four sessions with 24 subjects each; the participants were students from all different fields of study and were recruited using the software ORSEE (Greiner 2004); for an overview of the treatments and summary statistics see tables A.1 and A.2 in the appendix. After having completed the main experiment, subjects answered a set of post-experimental questions on individual characteristics and attitudes. At this point, we conducted a set of incentivized post-experimental tasks, including a question on risk aversion (Dohmen et al. 2011) and tasks to measure distributional preferences (Balafoutas et al. 2012), loss aversion (Fehr and Goette 2007), and ambiguity aversion. One of the incentivized post-experimental tasks was randomly selected for payment on top of the earnings from the main experiment. On average, subjects earned 29 Euros in total and a session lasted approximately 90 minutes.

we made sure that each possible combination of the drift parameters $\left(\alpha_{i}, \alpha_{j}\right)$ occurs at least once (recall that $\left.\alpha_{k} \in\{-1.5,0,1.5\}\right)$ to ensure some variation in terms of the observed portfolio pairs; otherwise, the portfolio selection was completely random.

${ }^{14}$ The payoff (in experimental currency) for an estimate $\tilde{y}_{i, \hat{r}}(\hat{t})$ is $\max \left\{250-0.1\left(y_{i, \hat{r}}(T)-\tilde{y}_{i, \hat{r}}(\hat{t})\right)^{2}, 25\right\}$.

${ }^{15}$ In sessions with the control question offering the choice of receiving as a payment the final value of a new randomly generated portfolio, a subject receives either the final value of the assigned portfolio or the final value of a new portfolio, depending on his choice at the selected point in time $\hat{t}$. Recall that even if a subject opts for a new portfolio at some point in time, he nevertheless observes the initially assigned portfolio of the current round until $T$ and answers all questions on this initially assigned portfolio. Only at the end of the experiment will a subject get to see the alternative portfolio in case he chose an alternative portfolio at the randomly selected point in time $\hat{t}$. 


\subsection{Predictions}

Individuals form beliefs about their final portfolio value based on information received during the experiment; these beliefs affect an individual's expected utility (satisfaction). Using pairwise treatment comparisons we analyze how information about others affects individual beliefs and what this may imply when individuals have concerns about relative standing.

The first prediction focuses on the effect of additional information (a second observed portfolio) on individuals' beliefs about the own income. Individual portfolios are drawn independently; thus, if subjects know the exact income-generating process, individual beliefs about the own final income should be independent of any additional information on other portfolios and, hence, not be different in the treatments BASE and P2-INFO. In the experiment, even though subjects do not learn the exact income-generating process, they are shown a "probability distribution" of possible portfolio values (see the graph in the instructions in Appendix C). This approach closely maps a situation in which individuals hold a common prior about the income-generating process. However, even though it is common knowledge that the portfolios are independently and randomly assigned, subjects may still perceive the additional information in P2-INFO as informative and adapt their beliefs according to the additional signals received. If the individuals expect some common (but unknown) trend in the income-generating processes observed, this yields the following testable prediction which is in line with Hirschman (1973).

Prediction 1 ("Information effect") (i) In the P2-INFo treatment, observing an additional portfolio $P_{j}$ with value $y_{j}(t)<y_{i}(t)$ lowers individual $i$ 's beliefs about $y_{i}(T)$, compared to the control group in the BASE treatment.

(ii) In the $\mathrm{P} 2$-INFo treatment, observing an additional portfolio $P_{j}$ with value $y_{j}(t)>y_{i}(t)$ increases individual $i$ 's beliefs about $y_{i}(T)$, compared to the control group in the BASE treatment.

By comparing the individuals' beliefs about the final portfolio value in P2-INFO and in BASE we test Prediction 1 against the alternative hypothesis that individuals interpret the additional information on a second portfolio as uninformative for their own final income. Taking the own current portfolio value as a benchmark we analyze the cases of $y_{j, r}(t)<y_{i, r}(t)$ and $y_{j, r}(t)>y_{i, r}(t)$ separately to allow for an asymmetric effect of observing a second portfolio with a higher and with a lower value, respectively. Since a subset of individuals across treatments observe the same portfolios, the comparison of P2-INFO to BASE controls for the information received on the own portfolio in the respective round and in previous rounds. 
Second, holding constant the information that subjects receive about the own income, observing signals about another individual's income prospects may have a direct effect on own satisfaction whenever individuals care about their relative income.

Prediction 2 ("Income-comparison effect") (i) In the P2-INCOME treatment, observing information on individual $j$ 's income lowers individual $i$ 's satisfaction whenever $y_{j}(t)>$ $y_{i}(t)$, compared to the control group in the P2-INFO treatment.

(ii) In the P2-INCOME treatment, observing information on individual $j$ 's income increases individual $i$ 's satisfaction whenever $y_{j}(t)<y_{i}(t)$, compared to the control group in the P2INFO treatment.

Controlling for the "information effect" on beliefs about the own income, average satisfaction should be lower when individuals observe that another participant has a relatively high current portfolio value and is, hence, likely to have a higher income (Prediction 2(i)); average satisfaction should be higher when observing that others are worse off (Prediction 2(ii)). If, instead, individuals do not care about income comparison then the average satisfaction in P2-INCOME and in P2-INFO should be the same (both for $y_{j}(t)>y_{i}(t)$ and for $\left.y_{j}(t)<y_{i}(t)\right)$ since the information received about the own income is identical in both treatments. Again, we test whether there is an asymmetric effect on own satisfaction when observing higher and lower income of others, respectively.

To summarize, a comparison of P2-INFO and BASE identifies the purely informational value that observing additional signals on the income-generating process may have for the expectations about the own income (the term $\partial E_{i}\left[y_{i} \mid\left(s_{i}, s_{j}\right)\right] / \partial s_{j}$ in $(2)$ ), in situations in which status concerns do not directly take effect. A comparison of P2-InCOME and P2-INFO reveals whether signals about the actual income of others affect an individual's satisfaction (the term $\lambda_{i} \partial E_{i}\left[y_{j} \mid\left(s_{i}, s_{j}\right)\right] / \partial s_{j}$ in $\left.(2)\right)$, controlling for the effect on $E_{i}\left[y_{i} \mid\left(s_{i}, s_{j}\right)\right]$. By construction, the direct effect on satisfaction is zero in the P2-INFO treatment where the additional portfolio observed is not payoff-relevant for any other participant. However, even in the P2-INFO treatment individuals may draw conclusions on the income of others when observing an additional portfolio, for instance, because they believe that the second portfolio is generally informative regarding the portfolios that other participants may be assigned to. In this case, satisfaction might already be affected by additional information in P2-INFO; therefore, the comparison of P2-INCOME and P2-INFO may underestimate the "incomecomparison effect" of observing oneself as being ahead or behind in terms of expected income relative to the assigned co-player. 


\section{Results}

In a nutshell the empirical results show that when subjects observe bad additional information (a second portfolio with a lower current value), they lower their expectations of their own income prospects. Observing good additional information has, however, no statistically measurable effect on beliefs about own income. Moreover, observing signals that indicate a lower expected income than others has a negative effect on individual satisfaction, while observing signals that indicate a higher expected income than others has no statistically measurable effect on satisfaction. Combining these effects shows that information-based effects and direct income-comparison effects may offset each other when the uncertainty over the income is large; their joint effect on satisfaction is statistically indistinguishable from zero at early points in time within a round. But as the uncertainty is reduced, income-comparison effects dominate the value of information on the others' experiences for the own income prospects such that, in total, satisfaction goes down when observing that others most likely earn more.

Before we derive these results in more detail it is important to note that the self-reported measures for beliefs and satisfaction are sensitive to changes in the information observed and react as predicted to the parameters of the experiment. For instance, stated beliefs and satisfaction levels shift upwards under higher (though unknown) trends of the incomegenerating process (compare the histograms in Figure A.1 of Appendix A; the resulting cumulative distribution functions can be ranked in terms of first-order stochastic dominance). Similarly, stated beliefs and satisfaction are significantly positively correlated (the correlation coefficient is 0.71). The same is true (i) for stated beliefs and the current or the final (not yet known) portfolio value (correlation coefficients are 0.88 and 0.70 , respectively) and (ii) for stated satisfaction and the current or the final portfolio value (correlation coefficients are 0.78 and 0.65 , respectively). The correlation of stated beliefs and the final portfolio value becomes stronger as the points in time $t$, in which the portfolio is observed, approach the end point $T$ of a round (the correlation coefficient increases from 0.43 to 0.93 ): As to be expected, the beliefs become more accurate when the uncertainty decreases. ${ }^{16}$ Finally, we can use as a plausibility check the incentivized control question on the option to receive as

\footnotetext{
${ }^{16}$ For the subsequent analysis we exclude four (out of 288) subjects which either always stated "implausible" beliefs below 10 (they presumably used a wrong scale given the fact that final portfolio values were between 81 and 585) or always reported the exact same number for their satisfaction. While for the latter subjects it is conceptually less clear whether or not these subjects should be excluded, our results are robust to including them. Since we did not want to bias the subjects' priors by showing them specific portfolios, we could not implement pre-tests before the main experiment. In general, however, the subjects' choices together with their answers to the post-experimental questions indicate that the vast majority of subjects understood the experimental tasks.
} 

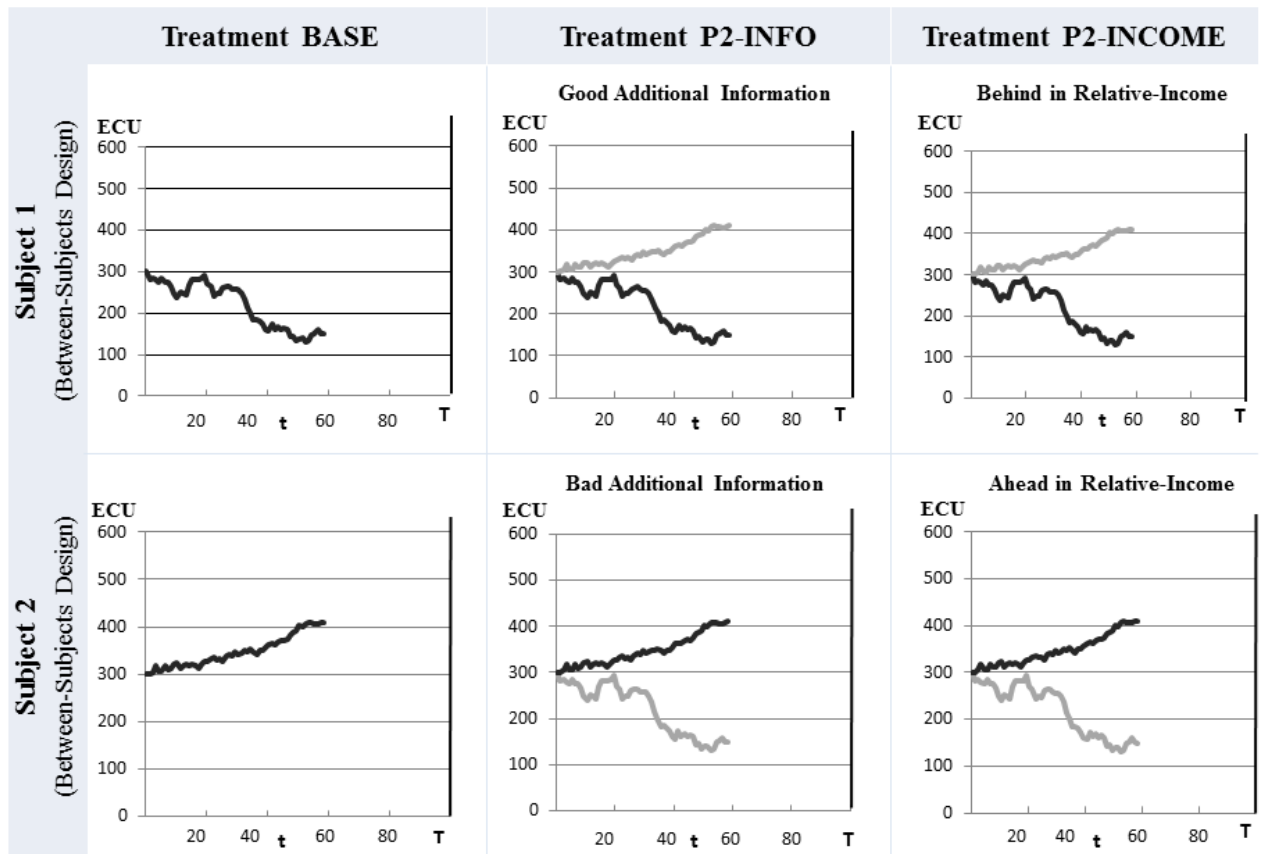

Note: "Own" portfolio marked in black; second portfolio marked in grey.

Figure 1: Identification strategy.

income the final value of a new, randomly drawn portfolio. Here, subjects are more likely to prefer the final value of their current portfolio as their income if (i) their beliefs are higher (the correlation coefficient of this choice and reported beliefs is 0.63), and (ii) their reported satisfaction is higher (the correlation coefficient of this choice and satisfaction is 0.62). ${ }^{17}$

\subsection{Information effects}

First we are interested in the effect of information about another income-generating process on the beliefs about the own end-of-period portfolio value (Prediction 1). To assess the effect of observing additional signals in the form of an additional portfolio it is crucial to perfectly control for all information on the own portfolio. We compare the beliefs in the P2INFO treatment to the beliefs in the BASE treatment in which reference groups of subjects observe the exact same own portfolios as in P2-INFO but no additional portfolio within a round. Moreover, we separate the "information effect" of situations in which subjects observe

\footnotetext{
${ }^{17}$ More precisely, for satisfaction, the correlation coefficient is 0.60 if the choice to be assigned a new portfolio at the end of the experiment is binding and is 0.64 if the choice of a new portfolio is only "hypothetical" and is not actually implemented (and thus has no payoff consequence). Recall that each of these variants of the control question was used in approximately half of the sessions.
} 


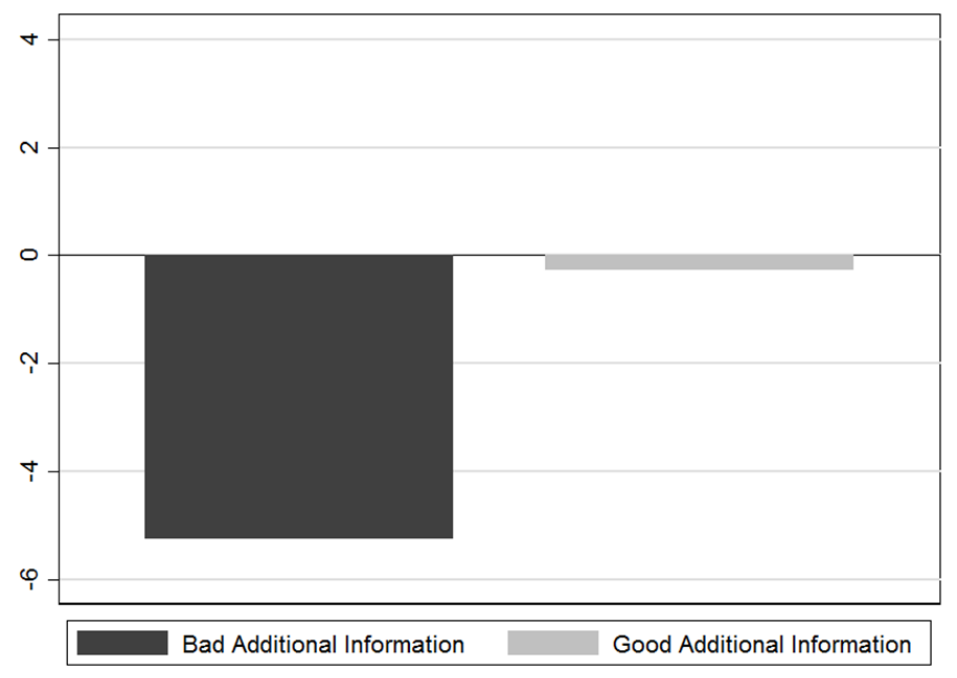

Figure 2: Change in average beliefs (in experimental currency) from BASE to P2-INFO.

(i) "good additional information" (the second portfolio has a higher current value, that is, $\left.y_{j}(t)>y_{i}(t)\right)$ and (ii) "bad additional information" (the second portfolio has a lower current value, that is, $\left.y_{j}(t)<y_{i}(t)\right)$. Figure 1 illustrates our identification strategy of comparing beliefs in P2-INFO (middle column) to those in BASE (left column), for a given own portfolio.

We start with a simple comparison of average stated beliefs in treatments BASE and P2Info; see also Table A.2 in Appendix A for descriptive statistics. Splitting the observations into situations of good and bad additional information, ${ }^{18}$ Figure 2 suggests partial evidence for Prediction 1: While bad additional information lowers average beliefs in P2-INFO compared to BASE, good additional information shows no evident effect on average beliefs. In the following we further investigate and confirm this observed asymmetry in the reaction to additional information.

To test Prediction 1 on the effect of additional information we estimate a crossed-effects linear regression model on the sample of the observations from BASE and P2-INFO. ${ }^{19}$ Using as a dependent variable subject $i$ 's beliefs belie $f_{i, r}(t)$ about the own end-of-period portfolio

\footnotetext{
${ }^{18}$ Observations in BASE are split accordingly (even though the second portfolio is not observed) such that the treatment group in P2-INFO and the control group in BASE observe the exact same own current portfolio values (income prospects), under both good and bad additional information.

${ }^{19}$ The crossed-effects model allows us to specify random effects at the subject level and additional random effects at the portfolio level. The random effects at the subject level account for time-constant subjectspecific effects. Random effects at the portfolio level allow us to reduce potential portfolio noise in the error term. Note that all results are qualitatively robust to using a simple random-effects regression model or a pooled OLS model with clustered standard errors on subject and session level.
} 
value as reported at point in time $t$ of round $r$, our main specification is given by

$$
\begin{aligned}
\text { belief }_{i, r}(t)=\beta_{0}+\beta_{1} y_{i, r}(t)+\beta_{2} P 2 & -I N F O+\beta_{3} I_{y_{j, r}(t)>y_{i, r}(t)} \\
& +\beta_{4} I_{y_{j, r}(t)>y_{i, r}(t)} \times P 2-I N F O+\gamma X_{i, r}(t)+\varepsilon_{i, r}(t) .
\end{aligned}
$$

The main variables of interest are the treatment variable P2-INFO (which is equal to one for observations from the P2-INFO treatment and zero otherwise) and the indicator variable $I_{y_{j, r}(t)>y_{i, r}(t)}$ which is equal to one in situations of good additional information (if the second portfolio $j$ has a higher current value than subject $i$ 's portfolio) and equal to zero otherwise. ${ }^{20}$ Moreover, we interact the dummy P2-INFO with the indicator $I_{y_{j, r}(t)>y_{i, r}(t)}$, and we include the observed own current portfolio value $y_{i, r}(t)$ as an explanatory variable as well as a vector $X_{i, r}(t)$ of additional control variables. ${ }^{21}$ Thus, in equation (5), $\beta_{2}$ measures the effect of bad information (the treatment effect if $\left.I_{y_{j, r}(t)>y_{i, r}(t)}=0\right)$ and $\beta_{2}+\beta_{4}$ measures the effect of good information (the treatment effect if $\left.I_{y_{j, r}(t)>y_{i, r}(t)}=1\right)$. The main estimation results are summarized in Table 1.

In specification 1 of Table 1, the estimated coefficient of P2-INFO is -11.74 and significant at the $5 \%$ level ( $p$-value $<0.041)$. Hence, observing a second portfolio with a lower value significantly lowers the subjects' beliefs in the P2-INFO treatment, compared to the reference group (with identical own portfolios) in BASE. Second, the sum of the coefficients of $I_{y_{j, r}(t)>y_{i, r}(t)} \times P 2-I N F O$ and $P 2-I N F O$ is negative but statistically indistinguishable from zero $(p$-value $>0.199)$; observing a second portfolio with a higher value does not yield a statistically measurable effect on stated beliefs. ${ }^{22}$ Finally, the current value of the own portfolio $\left(y_{i, r}(t)\right)$ has strong explanatory power with a positive coefficient that is close to one, which also confirms the validity of the measure of beliefs. Even though the estimated coefficient of P2-INFO and the corresponding significance level decrease slightly ( $p$-value $<0.077$ ), these findings are confirmed in specification 2 which adds individual-specific control variables

\footnotetext{
${ }^{20}$ The case of the exact same current portfolio values $\left(y_{j, r}(t)=y_{i, r}(t), t>0\right)$ never occurs in the data.

${ }^{21}$ We include fixed effects for the round $r$ of the experiment, for the point in time $t$ within a round and for the sequence in which subject $i$ observes the assigned 10 portfolios as well as session fixed effects. Moreover, some specifications further include controls such as gender, age, and a dummy for business-related fields of study as well as individual-specific characteristics elicited in an extended post-experimental questionnaire (including measures for risk aversion, loss aversion, ambiguity aversion, distributional preferences, and selfreported measures for optimism and patience).

${ }^{22}$ Note that the negative coefficient of $I_{y_{j, r}(t)>y_{i, r}(t)}$ results from the fact that the comparison group in the BASE treatment has a relatively low own current portfolio value whenever $y_{j, r}(t)>y_{i, r}(t)$. In other words, situations in which good additional information is observed are, at the same time, situations in which the own portfolio value, and hence beliefs, are relatively low (compare also rows 1 and 2 in Figure 1). The significantly positive coefficient of the interaction term $I_{y_{j, r}(t)>y_{i, r}(t)} \times P 2-I N F O$ confirms a treatment difference of BASE and P2-INFO with respect to comparisons of situations where the second portfolio would be relatively low and high, respectively.
} 


\begin{tabular}{|c|c|c|c|c|c|}
\hline & $\begin{array}{c}(1) \\
\text { belief }\end{array}$ & $\begin{array}{c}(2) \\
\text { belief }\end{array}$ & $\begin{array}{c}(3) \\
\text { belief }\end{array}$ & $\begin{array}{c}(4)^{a} \\
\text { belief }\end{array}$ & $\begin{array}{c}(5)^{b} \\
\text { belief }\end{array}$ \\
\hline$y_{i, r}(t)$ & $\begin{array}{c}0.848^{* * *} \\
(0.013)\end{array}$ & $\begin{array}{c}0.848^{* * *} \\
(0.013)\end{array}$ & $\begin{array}{c}0.814^{* * *} \\
(0.017)\end{array}$ & $\begin{array}{c}0.900^{* * *} \\
(0.026)\end{array}$ & $\begin{array}{c}0.867^{* * *} \\
(0.024)\end{array}$ \\
\hline P2-INFO & $\begin{array}{c}-11.74^{* *} \\
(5.740)\end{array}$ & $\begin{array}{r}-10.55^{*} \\
(5.972)\end{array}$ & $\begin{array}{l}-8.336 \\
(5.885)\end{array}$ & $\begin{array}{l}-1.418 \\
(7.041)\end{array}$ & $\begin{array}{l}-9.426 \\
(7.318)\end{array}$ \\
\hline$I_{y_{j, r}(t)>y_{i, r}(t)}$ & $\begin{array}{c}-6.762^{* * *} \\
(2.114)\end{array}$ & $\begin{array}{c}-6.764^{* * *} \\
(2.114)\end{array}$ & & & \\
\hline$I_{y_{j, r}(t)>y_{i, r}(t)} \times \mathrm{P} 2$-INFO & $\begin{array}{l}4.364^{* *} \\
(2.063)\end{array}$ & $\begin{array}{l}4.364^{* *} \\
(2.063)\end{array}$ & & & \\
\hline$\Delta_{y_{j, r}(t)-y_{i, r}(t)}$ & & & $\begin{array}{c}-12.99^{* * *} \\
(2.928)\end{array}$ & $\begin{array}{l}-7.45 \\
(5.712)\end{array}$ & $\begin{array}{c}-19.59^{* * *} \\
(5.541)\end{array}$ \\
\hline$\Delta_{y_{j, r}(t)-y_{i, r}(t)} \times \mathrm{P} 2-\mathrm{INFO}$ & & & $\begin{array}{l}4.021^{* *} \\
(1.947)\end{array}$ & $\begin{array}{l}-4.954 \\
(5.017)\end{array}$ & $\begin{array}{l}8.613^{*} \\
(4.731)\end{array}$ \\
\hline Constant & $\begin{array}{c}82.13^{* * *} \\
(7.515)\end{array}$ & $\begin{array}{c}82.76^{* * *} \\
(7.571)\end{array}$ & $\begin{array}{c}89.66^{* * *} \\
(8.015)\end{array}$ & $\begin{array}{c}51.19^{* * *} \\
(11.21)\end{array}$ & $\begin{array}{c}86.02^{* * *} \\
(10.32)\end{array}$ \\
\hline $\begin{array}{l}\text { Individual } \\
\text { controls }\end{array}$ & No & Yes & Yes & Yes & Yes \\
\hline $\begin{array}{l}\text { Time and session } \\
\text { fixed effects }\end{array}$ & Yes & Yes & Yes & Yes & Yes \\
\hline$N$ & 7600 & 7600 & 7600 & 3800 & 3800 \\
\hline
\end{tabular}

${ }^{a}$ Subsample of good additional information $\left(\Delta_{y_{j, r}(t)-y_{i, r}(t)}>0\right)$.

${ }^{b}$ Subsample of bad additional information $\left(\Delta_{y_{j, r}(t)-y_{i, r}(t)}<0\right)$.

Note: Crossed-effects regression model with random effects on subject and portfolio level. Observations from treatments BASE and P2-INFO. Dependent variable: beliefs. Standard errors in parentheses, ${ }^{*} \mathrm{p}<0.10,{ }^{* *} \mathrm{p}<0.05,{ }^{* * *} \mathrm{p}<0.01$. "Individual controls" include gender, age, whether the field of study is business related, risk aversion, loss aversion, ambiguity aversion, distributional preferences, optimism, and patience. "Time and session fixed effects" include round fixed effects, point-in-time fixed effects, fixed effects for the sequence in which the selected portfolios are shown, and session fixed effects.

Table 1: Information effect: Regression results. 
elicited after the main part of the experiment.

As a natural extension beyond the binary case of good or bad additional information, specifications 3 to 5 include as an explanatory variable the difference between the current value of the second portfolio and the own current portfolio value $\left(y_{j, r}(t)-y_{i, r}(t)\right)$. Hence, positive (negative) values of this difference indicate good (bad) additional information and higher values indicate better additional signals. We normalize this difference in order to separate the effects of additional information from time trends within a round (since all portfolios start with the same value, the range of $y_{j, r}(t)-y_{i, r}(t)$ is usually increasing in $t$; at the same time, uncertainty is reduced) and define the normalized difference by $\Delta_{y_{j, r}(t)-y_{i, r}(t)}{ }^{23}$ Now, the treatment effect of observing an additional portfolio is captured by the coefficients of $P 2-I N F O$ and the interaction term $\Delta_{y_{j, r}(t)-y_{i, r}(t)} \times P 2-I N F O$. In specification 3 , the estimated coefficient of P2-INFO is -8.336 and indicates that beliefs are, for average portfolios, slightly lower in P2-INFO than in BASE. Moreover, higher values of the second portfolio compared to the own current portfolio value have a significantly positive effect on beliefs in P2-INFO, again compared to the reference group in BASE (the estimated coefficient of the interaction term $\Delta_{y_{j, r}(t)-y_{i, r}(t)} \times P 2-I N F O$ is positive and significant at the $5 \%$ level $) .{ }^{24}$ Separating the sample into subsamples of good additional information (where $\Delta_{y_{j, r}(t)-y_{i, r}(t)}$ is positive) and bad additional information (where $\Delta_{y_{j, r}(t)-y_{i, r}(t)}$ is negative) shows that the observed effect of additional information (in specification 3) is driven by bad information and is, again, asymmetric: there is no statistically measurable treatment effect in case of good additional information (specification 4) but there is a significant treatment effect in case of bad additional information (specification 5). ${ }^{25}$

While specifications 3 to 5 assume a linear effect of the difference $\Delta_{y_{j, r}(t)-y_{i, r}(t)}$, we can alternatively extend the interaction model of specifications 1 and 2 of Table 1 to disaggregate the effect of observing a second portfolio on beliefs. If we use dummy variables to separate cases of "very good," "rather good," "rather bad," and "very bad" information based on quartiles of the difference $y_{j, r}(t)-y_{i, r}(t)$, we find that lower additional signals lead to lower beliefs (see tables B.2 and B.3 in Appendix B for the estimation results). This effect appears to be monotonic, going from very good to very bad additional information, and is strongest

\footnotetext{
${ }^{23}$ More precisely, we divide $y_{j, r}(t)-y_{i, r}(t)$ by the maximum value of $\left|y_{j, r}(t)-y_{i, r}(t)\right|$ over all portfolio combinations $(i, j)$ at point in time $t$; thus, $\Delta_{y_{j, r}(t)-y_{i, r}(t)}$ takes values between -1 and 1 at each point in time $t$. Alternatively, the normalization could use the median or mean of the absolute distance over all portfolios, which yields qualitatively very similar results.

${ }^{24} \mathrm{An} F$-test shows that coefficients of $P 2-I N F O$ and $\Delta_{y_{j, r}(t)-y_{i, r}(t)} \times P 2-I N F O$ are jointly significant at the $5 \%$ level ( $p$-value is 0.04$)$.

${ }^{25}$ This holds for both treatment variables of interest as well as their joint effect; the $p$-value of an $F$ test on the joint significance of the estimated coefficients of $P 2-I N F O$ and $\Delta_{y_{j, r}(t)-y_{i, r}(t)} \times P 2-I N F O$ is 0.53 in specification 4 and 0.03 in specification 5 .
} 
when observing very bad additional information.

Result 1 Additional signals of uncertain informativeness affect the beliefs about the own income prospects. Bad additional information (signals $y_{j}(t)<y_{i}(t)$ ) leads to a downward adjustment of beliefs while good additional information (signals $y_{j}(t)>y_{i}(t)$ ) has no statistically significant effect on beliefs.

Generally, we find that subjects react to additional information even when they "know" the probability distribution of their own income and when the informativeness of additional information is uncertain. This uncertain informativeness of additional information is an important feature of our experiment as we do not "frame" subjects into one or the other direction by inducing them to believe in some particular correlation structure. Nevertheless, we find an effect of additional information but only in specific situations: subjects lower their beliefs about their own income prospects after observing additional portfolios with relatively low values. But when observing additional portfolios with relatively high values subjects do not adjust their beliefs in a statistically measurable way. In light of the detailed information provided on the distribution of possible portfolios (compare the graph in the experimental instructions in Appendix C) and the uncertain informativeness of the additional signals the results appear to be even stronger. Responses are likely to be more pronounced when subjects know the correlations between future incomes with certainty.

\subsection{Income-comparison effects}

In this section we analyze how satisfaction is affected when subjects observe signals about another subject's income prospects (Prediction 2). By comparing the P2-Income treatment to the P2-INFo treatment, we can perfectly control for all signals that could be directly informative for the own income. ${ }^{26}$ Figure 1 illustrates our identification strategy using the treatments P2-INFo (middle column) and P2-InCOME (right column), which now distinguishes between situations in which subjects are behind in terms of relative income $\left(y_{j, r}(t)>y_{i, r}(t)\right)$ and situations in which subjects are ahead in terms of relative income $\left(y_{j, r}(t)<y_{i, r}(t)\right)$, that is, between unfavorable and favorable income comparisons.

For an initial overview of the data, consider the change in simple means of reported satisfaction when comparing the P2-INCOME treatment to the reference observations in the P2-Info treatment. ${ }^{27}$ As Figure 3 indicates, we find partial evidence of Prediction

\footnotetext{
${ }^{26}$ Recall that the only difference between the two treatments is that the second portfolio observed in P2INCOME is directly payoff-relevant for another subject and should therefore have an effect on satisfaction, while it should have no effect (or a weaker effect) in P2-INFO where it is not payoff-relevant for any other subject.

${ }^{27}$ See also Table A.2 in Appendix A for descriptive statistics.
} 


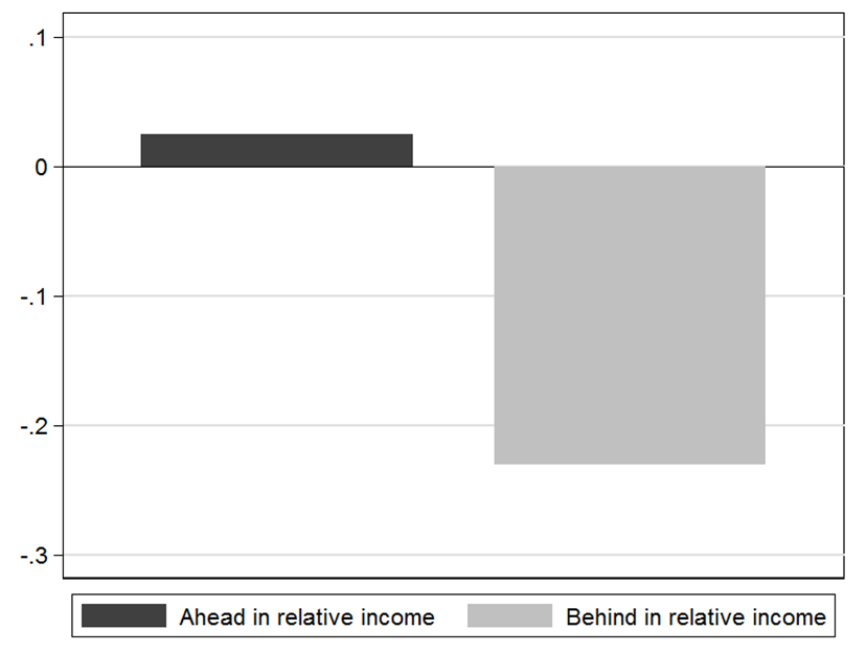

Figure 3: Change in satisfaction from treatment P2-InFo to P2-InCOME.

2: when subjects are behind in the sense that they have a lower current portfolio value $\left(y_{j, r}(t)>y_{i, r}(t)\right)$, their satisfaction is lower than in the comparison group of P2-INFO, while being ahead $\left(y_{j, r}(t)<y_{i, r}(t)\right)$ has no evident effect on average satisfaction.

To further investigate this result we estimate a crossed-effects linear regression model similar to Section 3.1, on the sample of the observations from the treatments P2-INFO and P2-INCOME: $:^{28,29}$

$$
\begin{aligned}
\text { satisfaction }_{i, r}(t) & =\beta_{o}+\beta_{1} \text { belief }_{i, r}(t)+\beta_{2} y_{i, r}(t)+\beta_{3} P 2-I N C O M E \\
& +\beta_{4} I_{y_{j, r}(t)>y_{i, r}(t)}+\beta_{5} I_{y_{j, r}(t)>y_{i, r}(t)} \times P 2-I N C O M E+\boldsymbol{\beta} X_{i, r}+\varepsilon_{i, r}(t)
\end{aligned}
$$

The dependent variable satisfaction f $_{i, r}(t)$ represents subject $i$ 's reported satisfaction at point in time $t$ of round $r$. Our main variables of interest are the treatment dummy P2-INCOME (which indicates observations stemming from the P2-INCOME treatment) and the interaction of $P 2-I N C O M E$ with the indicator variable $I_{y_{j, r}(t)>y_{i, r}(t)}$, which now indicates that subject $i$

\footnotetext{
${ }^{28}$ Note that we pool the observations from the sessions with the two different versions of the incentivized control question for the measure of satisfaction (the choice to receive as income the final value of another portfolio; compare Section 2.2), as the results obtained are very similar. See Table B.1 in the appendix for estimations that separate these two types of sessions.

${ }^{29}$ The reasoning for using a crossed-effects model is identical to the previous subsection. All results of this section are qualitatively robust to using a simple random-effects regression model, a random-effects Tobit model or a pooled OLS model with two-dimensional clustered standard errors on subjects and session level. As satisfaction is an ordinal concept we also apply a random-effects ordered probit model. In line with the findings of Ferrer-i-Carbonell and Frijters (2004) we find that the results are qualitatively robust.
} 
is behind in terms of current portfolio value $\left(y_{j, r}(t)>y_{i, r}(t)\right)$. Just as in estimation equation (5) for the information effect, additional explanatory variables are the current own portfolio value $y_{i, r}(t)$ and the set $X_{i, r}(t)$ of controls (time and session fixed effects and individualspecific controls). Moreover, we include the reported beliefs belie $f_{i, r}(t)$ as an explanatory variable. In equation (6), the coefficient $\beta_{3}$ reflects the treatment effect of being ahead (when $I_{y_{j, r}(t)>y_{i, r}(t)}=0$ ) compared to the reference group in P2-INFO, and the sum $\beta_{3}+\beta_{5}$ corresponds to the treatment effect of being behind (when $I_{y_{j, r}(t)>y_{i, r}(t)}=1$ ), again compared to the reference group in P2-INFO.

In specification 1 of Table 2, the estimated coefficient of P2-INCOME is -0.179 and insignificant $(p$-value $>0.48)$; hence, we conclude that being ahead has no statistically measurable effect on satisfaction. The treatment effect of being behind measured by the sum of the coefficients of $P 2-I N C O M E$ and its interaction term with $I_{y_{j, r}(t)>y_{i, r}(t)}$ has the expected negative sign (-0.415) and is borderline significant ( $p$-value $<0.105)$. When adding individual-specific controls from the post-experimental questionnaire as in specification 2 , the treatment effect of being behind becomes slightly stronger (-0.447) and significant at the $10 \%$ level ( $p$-value $<0.074$ ); the treatment effect of being ahead remains insignificant. ${ }^{30}$ Moreover, the current value of the own portfolio $\left(y_{i, r}(t)\right)$ and the beliefs about the own end-of-period portfolio value $\left(\right.$ belie $\left.f_{i, r}(t)\right)$ have strong explanatory power throughout all specifications with positive coefficients that are significant at the $1 \%$ level. Hence, even after controlling for the current portfolio value, differences in beliefs about the final income translate into differences in satisfaction levels.

In line with Section 3.1 above we can extend the binary case of being ahead or behind and directly investigate the treatment effect of the difference between the two observed portfolio values (the variable $\left.\Delta_{y_{j, r}(t)-y_{i, r}(t)}\right) .{ }^{31}$ In specification 3 , the estimated coefficient of the indicator variable $P 2-I N C O M E$ is -0.321 ; hence, for average portfolios the stated satisfaction is slightly lower in P2-INCOME than in P2-INFO. More importantly, the estimated coefficient of the interaction term $\Delta_{y_{j, r}(t)-y_{i, r}(t)} \times P 2-I N C O M E$ is -0.244 and significant at the $1 \%$ level: An increasing difference between the current portfolio values of subjects $j$ and $i$ leads to significantly lower satisfaction levels of subject $i$, compared to the reference group in P2-

\footnotetext{
${ }^{30}$ The significantly negative coefficient of $I_{y_{j, r}(t)>y_{i, r}(t)}$ reflects the fact that, within P2-INFO, a subject's own portfolio is comparably low in situations of $y_{j, r}(t)>y_{i, r}(t)$; hence, satisfaction is also low. Since the interaction term of P2-INCOME with $I_{y_{j, r}(t)>y_{i, r}(t)}$ is significantly negative, this effect becomes significantly more pronounced within the P2-Income treatment, in line with the result of the negative treatment effect of being behind.

${ }^{31}$ We again normalize the difference $y_{j, r}(t)-y_{i, r}(t)$ using the maximum observed difference at a given point in time (see Section 3.1) in order to separate the effect of a higher difference in portfolio values from the time-related effects of an increasing difference $y_{j, r}(t)-y_{i, r}(t)$ within a round. Note again that normalizing the difference by the mean or the median yields very similar results.
} 


\begin{tabular}{|c|c|c|c|c|c|}
\hline & $\begin{array}{c}\text { (1) } \\
\text { satisfaction }\end{array}$ & $\begin{array}{c}(2) \\
\text { satisfaction }\end{array}$ & $\begin{array}{c}\text { (3) } \\
\text { satisfaction }\end{array}$ & $\begin{array}{c}(4)^{a} \\
\text { satisfaction }\end{array}$ & $\begin{array}{c}(5)^{b} \\
\text { satisfaction }\end{array}$ \\
\hline$y_{i, r}(t)$ & $\begin{array}{c}0.017^{* * *} \\
(0.001)\end{array}$ & $\begin{array}{c}0.017^{* * *} \\
(0.001)\end{array}$ & $\begin{array}{c}0.014^{* * *} \\
(0.001)\end{array}$ & $\begin{array}{c}0.021^{* * *} \\
(0.001)\end{array}$ & $\begin{array}{c}0.023^{* * *} \\
(0.001)\end{array}$ \\
\hline belief $_{i, r}(t)$ & $\begin{array}{c}0.004^{* * *} \\
(0.000)\end{array}$ & $\begin{array}{c}0.004^{* * *} \\
(0.000)\end{array}$ & $\begin{array}{c}0.004^{* * *} \\
(0.000)\end{array}$ & $\begin{array}{c}0.003^{* * *} \\
(0.000)\end{array}$ & $\begin{array}{c}0.003^{* * *} \\
(0.001)\end{array}$ \\
\hline P2-INCOME & $\begin{array}{l}-0.179 \\
(0.256)\end{array}$ & $\begin{array}{l}-0.207 \\
(0.247)\end{array}$ & $\begin{array}{l}-0.321 \\
(0.245)\end{array}$ & $\begin{array}{l}-0.277 \\
(0.282)\end{array}$ & $\begin{array}{l}-0.221 \\
(0.261)\end{array}$ \\
\hline$I_{y_{j, r}(t)>y_{i, r}(t)}$ & $\begin{array}{c}-0.863^{* * *} \\
(0.066)\end{array}$ & $\begin{array}{c}-0.862^{* * *} \\
(0.066)\end{array}$ & & & \\
\hline$I_{y_{j, r}(t)>y_{i, r}(t)} \times \mathrm{P} 2-\mathrm{INCOME}$ & $\begin{array}{c}-0.236^{* * *} \\
(0.065)\end{array}$ & $\begin{array}{c}-0.236^{* * *} \\
(0.065)\end{array}$ & & & \\
\hline$\Delta_{y_{j, r}(t)-y_{i, r}(t)}$ & & & $\begin{array}{c}-1.338^{* * *} \\
(0.094)\end{array}$ & $\begin{array}{c}-0.846^{* * *} \\
(0.169)\end{array}$ & $\begin{array}{c}-0.462^{* *} \\
(0.19)\end{array}$ \\
\hline$\Delta_{y_{j, r}(t)-y_{i, r}(t)} \times \mathrm{P} 2-\mathrm{INCOME}$ & & & $\begin{array}{c}-0.244^{* * *} \\
(0.062)\end{array}$ & $\begin{array}{c}-0.338^{* *} \\
(0.143)\end{array}$ & $\begin{array}{l}-0.054 \\
(0.153)\end{array}$ \\
\hline Constant & $\begin{array}{c}-0.825^{* * *} \\
(0.289)\end{array}$ & $\begin{array}{c}-0.808^{* * *} \\
(0.281)\end{array}$ & $\begin{array}{l}-0.305 \\
(0.307)\end{array}$ & $\begin{array}{c}-2.784^{* * *} \\
(0.467)\end{array}$ & $\begin{array}{c}-2.869^{* * *} \\
(0.409)\end{array}$ \\
\hline $\begin{array}{l}\text { Individual } \\
\text { controls }\end{array}$ & No & Yes & Yes & Yes & Yes \\
\hline $\begin{array}{l}\text { Time and session } \\
\text { fixed effects }\end{array}$ & Yes & Yes & Yes & Yes & Yes \\
\hline$N$ & 7600 & 7600 & 7600 & 3800 & 3800 \\
\hline
\end{tabular}

${ }^{a}$ Subsample of being behind $\left(\Delta_{y_{j, r}(t)-y_{i, r}(t)}>0\right)$.

${ }^{b}$ Subsample of being ahead $\left(\Delta_{y_{j, r}(t)-y_{i, r}(t)}<0\right)$.

Note: Crossed-effects regression model with random effects on subject and portfolio level. Observations from treatments P2-INFO and P2-INCOME. Dependent variable: satisfaction. Standard errors in parentheses, ${ }^{*} \mathrm{p}<0.10,{ }^{* *} \mathrm{p}<0.05,{ }^{* * *} \mathrm{p}<0.01$. "Individual controls" include gender, age, whether the field of study is business related, risk aversion, loss aversion, ambiguity aversion, distributional preferences, optimism, and patience. "Time and session fixed effects" include round fixed effects, point-in-time fixed effects, fixed effects for the sequence in which the selected portfolios are shown, and session fixed effects.

Table 2: Relative-income effect: Regression results. 
INFO where the exact same portfolios are observed but the second portfolio is not assigned to another subject. ${ }^{32}$ Specifications 4 and 5 confirm that the effect of changes in the difference of portfolio values is mainly driven by situations where subjects are behind: in the subsample of observations where subjects face unfavorable inequality $\left(\Delta_{y_{j, r}(t)-y_{i, r}(t)}>0\right.$; specification 4$)$ we observe a strong treatment effect. However, we do not observe a statistically significant treatment effect in the subsample of observations where subjects face favorable inequality $\left(\Delta_{y_{j, r}(t)-y_{i, r}(t)}<0 ;\right.$ specification 5$) .{ }^{33}$

As in Section 3.1 we can also extend the interaction model in specifications 1 and 2 of Table 2 to disaggregate the income-comparison effect into cases of being "far behind," "behind," "ahead," and "far ahead" (see tables B.4 and B.5 in Appendix B for the estimation results). The treatment effect of P2-INCOME appears to be monotonic and is strongest when subjects are "far behind" which, given the remaining uncertainty over the final income, makes it most likely that the final income will be lower.

Result 2 Observing signals about the income prospects of others affects individual satisfaction. Being behind (signals $y_{j}(t)>y_{i}(t)$ ) has a negative effect on satisfaction while being ahead (signals $y_{j}(t)<y_{i}(t)$ ) has no statistically significant effect on satisfaction.

Since subjects in the control group of P2-INFO observe the exact same portfolios, the treatment effect of observing another subject's portfolio value $y_{j}(t)$ controls for the own portfolio history as well as for any information on the own portfolio value which subjects derive from observing a second portfolio. However, even in P2-INFO subjects may interpret the second observed portfolio as a signal of, for instance, the likely income of the remaining participants of the experiment. Thus, the estimated treatment effect based on the difference between P2-Info and P2-Income may be seen as a lower bound for the direct incomecomparison effect. ${ }^{34}$

It is interesting to note that we find asymmetric results for additional information on beliefs (Result 1) and for relative-income considerations (Result 2). These asymmetries, however, appear as exact opposites. Beliefs are most strongly affected when subjects observe a lower additional portfolio (that is, receive bad additional information), while satisfaction is most strongly affected when subjects observe a higher additional portfolio of another subject

\footnotetext{
${ }^{32}$ An $F$-test shows that the coefficients of $P 2-I N C O M E$ and $\Delta_{y_{j, r}(t)-y_{i, r}(t)} \times P 2-I N C O M E$ are jointly significant at the $1 \%$ level ( $p$-value is 0.000$)$.

${ }^{33}$ In specifications 4 and 5 , the $F$-tests on the joint significance of $P 2-I N C O M E$ and $\Delta_{y_{j, r}(t)-y_{i, r}(t)} \times P 2-$ INCOME yield $p$-values of 0.018 and 0.692 , respectively.

${ }^{34}$ Note that we can check this possibility by comparing reported satisfaction in the P 2-INFO treatment to satisfaction in the BASE treatment. Running the specifications of Table 2 on observations from treatments BASE and P2-INFO, however, yields no significant difference in satisfaction levels, independent of whether the second portfolio observed has a higher or lower current portfolio value. Details are available on request.
} 
(that is, are behind). One possible interpretation could be that in either case subjects respond to the "bad prospect" rather than to the "good prospect." Put differently, while bad signals about the expected personal income and bad signals about the expected relative standing trigger significant reactions, good signals do not or less so.

\subsection{Combining informational and income-comparison effects}

Our experimental design not only separates purely informational effects and income-comparison effects when observing signals about the income of others, it also allows us to look at the interplay of the two potentially countervailing effects: taking both effects together, do good signals about others' experiences lead to higher or lower satisfaction levels in situations where the own income is uncertain? Does the total effect depend on the degree of uncertainty and is, hence, different at early points in time as compared to late points in time where in the latter there is less uncertainty and income differences have become stable?

To investigate the total effect of observing signals about the income of others we can directly compare satisfaction levels in the P2-INCOME treatment and in the BASE treatment, combining both informational effects and income-comparison effects. ${ }^{35}$ For this purpose we use the same estimation strategy as in the previous section (see, for instance, specification 3 of Table 2). ${ }^{36}$ We separate possible effects at early points in time within a round from effects at later points in time to allow for changes in the combined effect over time when the uncertainty over income naturally decreases. The first two columns of Table 3 present the main results of the combined treatment effects on satisfaction levels based on the sample of observations from BASE and P2-INCOME; specification 1 only includes observations from the first two points in time $t$ within a round for which satisfaction levels were elicited (situations of high uncertainty), while specification 2 is based on observations from the last two points in time $t$ within a round where the uncertainty over the own and the relative income is reduced. (Recall that there are four such points in time in total within a round.) The main variables of interest are the treatment dummy P2-INCOME and its interaction with the variable $\Delta_{y_{j, r}(t)-y_{i, r}(t)}$, which again denotes the (normalized) difference between subject $j$ 's and subject $i$ 's current portfolio value and takes values between -1 and 1 . The coefficient of this interaction term reveals whether subjects in the treatment group P2-INCOME react differently to changes in the difference $y_{j, r}(t)-y_{i, r}(t)$, compared to the control group in BASE (where subjects do not observe the second portfolio but have been assigned the exact same

\footnotetext{
${ }^{35}$ The point becomes clear when considering Figure 1 once again. We simply move directly from the very left to the very right column of Figure 1 and thereby combine effects that additional signals may have on the expectations about the own income and about the relative income in one step.

${ }^{36}$ We do not include beliefs as explanatory variable since we are explicitly interested in the total effect which combines both purely informational effects and income-comparison effects.
} 
own portfolios).

In specification 1 of Table 3, neither of the estimated coefficients of the two treatment variables is significantly different from zero. ${ }^{37}$ Hence, at early points in time, satisfaction is not affected by the information on another subject's income. This changes, however, at a later point in time: In specification 2, the estimated coefficient of the interaction term $\Delta_{y_{j, r}(t)-y_{i, r}(t)} \times P 2-I N C O M E$ becomes larger in magnitude and significant at the $1 \%$ level. ${ }^{38}$ To summarize, initially subjects do not become unhappier if they observe that another subject has been assigned a portfolio that outperforms their own portfolio; over time, however, this changes and satisfaction strongly reacts to differences in income prospects. Note that the latter effect is, again, mostly driven by situations in which subjects are behind in terms of relative income.

Two apparent and mutually non-exclusive interpretations of this finding, which is in line with Hirschman's prediction, are the following. First, at early points in time, potential inequality is rather unstable since the final income is still uncertain; even if the other subject's current portfolio value is higher, there is still some probability that this can be reversed. At later points in time, however, persisting differences in current portfolio values translate, with high likelihood, into inequality of final incomes. Second, the uncertainty over the own income in early points in time makes purely informational effects of observing another portfolio more important; as discussed in Section 2.1, however, such information effects can countervail the income-comparison effects. When the own final income becomes much less uncertain (as at late points in time), we would also expect those information effects to be much weaker and dominated by the income-comparison effects. To address the first interpretation, specifications 3 and 4 of Table 3 analyze how the isolated income-comparison effect (the treatment effect of P2-Income compared to P2-InFo) changes over time. In contrast to the combined effect in specifications 1 and 2, the income-comparison effect turns out to be already significant at an early point in time and is quite stable over time. ${ }^{39}$ Even in situations with high uncertainty, satisfaction significantly reacts to increased inequality, given that we control for the informational effects on own expected income using P2-INFO as a control group. Looking at the dynamics of the information effects as in specifications 5 and 6, however, yields some support for Hirschman's idea: the isolated information effect (the treatment effect of P2-INFO on beliefs about the own income, compared to BASE) is

\footnotetext{
${ }^{37} \mathrm{An} F$-test shows that the coefficients of P2-INCOME and $\Delta_{y_{j, r}(t)-y_{i, r}(t)} \times P 2-I N C O M E$ are jointly insignificant (p-value 0.299).

${ }^{38} \mathrm{An} F$-test shows that the coefficients of P2-INCOME and $\Delta_{y_{j, r}(t)-y_{i, r}(t)} \times P 2-I N C O M E$ are jointly significant at the $1 \%$ level ( $p$-value is 0.000 ). Note that qualitatively very similar results on the dynamics are obtained when running estimations separately for each point in time.

${ }^{39}$ For both specifications 3 and 4 , the coefficients of P2-INCOME and $\Delta_{y_{j, r}(t)-y_{i, r}(t)} \times P 2-I N C O M E$ are jointly significant at the $1 \%$ level.
} 


\begin{tabular}{|c|c|c|c|c|c|c|}
\hline & \multicolumn{2}{|c|}{$\begin{array}{c}\text { Total effect } \\
\text { BASE vs. P2-INCOME }\end{array}$} & \multicolumn{2}{|c|}{$\begin{array}{l}\text { Income-comparison effect } \\
\text { P2-INFO vs. P2-INCOME }\end{array}$} & \multicolumn{2}{|c|}{$\begin{array}{l}\text { Information effect } \\
\text { BASE vs. P2-INFO }\end{array}$} \\
\hline & $\begin{array}{c}\text { Early } t \\
(1) \\
\text { satisfaction }\end{array}$ & $\begin{array}{c}\text { Late } t \\
(2) \\
\text { satisfaction }\end{array}$ & $\begin{array}{c}\text { Early } t \\
(3) \\
\text { satisfaction }\end{array}$ & $\begin{array}{c}\text { Late } t \\
(4) \\
\text { satisfaction }\end{array}$ & $\begin{array}{c}\text { Early } t \\
(5) \\
\text { belief }\end{array}$ & $\begin{array}{c}\text { Late } t \\
(6) \\
\text { belief }\end{array}$ \\
\hline$y_{i, r}(t)$ & $\begin{array}{c}0.016^{* * *} \\
(0.001)\end{array}$ & $\begin{array}{c}0.023^{* * *} \\
(0.001)\end{array}$ & $\begin{array}{c}0.016^{* * *} \\
(0.001)\end{array}$ & $\begin{array}{c}0.022^{* * *} \\
(0.001)\end{array}$ & $\begin{array}{c}0.815^{* * *} \\
(0.045)\end{array}$ & $\begin{array}{c}0.906^{* * *} \\
(0.018)\end{array}$ \\
\hline P2-INCOME & $\begin{array}{l}-0.077 \\
(0.277)\end{array}$ & $\begin{array}{l}-0.170 \\
(0.253)\end{array}$ & $\begin{array}{l}-0.171 \\
(0.263)\end{array}$ & $\begin{array}{c}-0.374 \\
(0.235)\end{array}$ & & \\
\hline$\Delta_{y_{j, r}(t)-y_{i, r}(t)}$ & $\begin{array}{c}-1.183^{* * *} \\
(0.193)\end{array}$ & $\begin{array}{c}-0.496^{* * *} \\
(0.160)\end{array}$ & $\begin{array}{c}-1.177^{* * *} \\
(0.194)\end{array}$ & $\begin{array}{c}-0.811^{* * *} \\
(0.165)\end{array}$ & $\begin{array}{c}-20.65^{* * *} \\
(7.067)\end{array}$ & $\begin{array}{l}-1.584 \\
(3.345)\end{array}$ \\
\hline $\begin{array}{l}\Delta_{y_{j, r}(t)-y_{i, r}(t)} \\
\quad \times \mathrm{P} 2-\mathrm{INCOME}\end{array}$ & $\begin{array}{c}-0.149 \\
(0.097)\end{array}$ & $\begin{array}{c}-0.402^{* * *} \\
(0.073)\end{array}$ & $\begin{array}{c}-0.298^{* * *} \\
(0.100)\end{array}$ & $\begin{array}{c}-0.250^{* * *} \\
(0.074)\end{array}$ & & \\
\hline P2-INFO & & & & & $\begin{array}{l}-11.27 \\
(7.695)\end{array}$ & $\begin{array}{l}-5.30 \\
(4.789)\end{array}$ \\
\hline $\begin{array}{l}\Delta_{y_{j, r}(t)-y_{i, r}(t)} \\
\quad \times \mathrm{P} 2-\mathrm{INFO}\end{array}$ & & & & & $\begin{array}{l}6.109 \\
(3.932)\end{array}$ & $\begin{array}{l}2.989 \\
(1.947)\end{array}$ \\
\hline Constant & $\begin{array}{r}-0.072 \\
(0.476)\end{array}$ & $\begin{array}{c}-1.940^{* * *} \\
(0.389)\end{array}$ & $\begin{array}{c}-0.103 \\
(0.476)\end{array}$ & $\begin{array}{c}-1.673^{* * *} \\
(0.409)\end{array}$ & $\begin{array}{c}92.42^{* * *} \\
(15.89)\end{array}$ & $\begin{array}{c}51.77^{* * *} \\
(7.285)\end{array}$ \\
\hline $\begin{array}{l}\text { Individual } \\
\text { controls }\end{array}$ & Yes & Yes & Yes & Yes & Yes & Yes \\
\hline $\begin{array}{l}\text { Time and session } \\
\text { fixed effects }\end{array}$ & Yes & Yes & Yes & Yes & Yes & Yes \\
\hline$N$ & 3760 & 3760 & 3800 & 3800 & 3800 & 3800 \\
\hline
\end{tabular}

Note: Crossed-effects regression model with random effects on subject and portfolio level. Dependent variables: satisfaction in specifications 1 to 4 and beliefs in specifications 5 and 6 . Standard errors in parentheses, ${ }^{*} \mathrm{p}<0.10,{ }^{* *} \mathrm{p}<0.05,{ }^{* * *} \mathrm{p}<0.01$. "Individual controls" include gender, age, whether the field of study is business related, risk aversion, loss aversion, ambiguity aversion, distributional preferences, optimism, and patience. "Time and session fixed effects" include round fixed effects, point-in-time fixed effects, fixed effects for the sequence in which the selected portfolios are shown, and session fixed effects.

Table 3: Total effect: Regression results. 
stronger at early points in time and fades out at late points in time. ${ }^{40}$ In particular, at early points in time, beliefs tend to be higher when the difference $y_{j, r}(t)-y_{i, r}(t)$ goes up (compare the coefficient of $\left.\Delta_{y_{j, r}(t)-y_{i, r}(t)} \times P 2-I N F O\right)$; higher beliefs, however, increase a subject's satisfaction (compare Table 2). Thus, the fact that the combined effect is indistinguishable from zero in early points in time may be interpreted as the information effect offsetting the income-comparison effect if and only if there is substantial uncertainty over the income prospects. $^{41}$

Result 3 The combined (information and income-comparison) effect is statistically indistinguishable from zero at early points in time where the two effects of observing additional information may offset each other. At late points in time, the relative-income effect dominates such that satisfaction decreases when observing oneself as behind in expected income $\left(y_{j}(t)>y_{i}(t)\right)$.

\subsection{Information effect under increased uncertainty}

Our main analysis on the effects of observing additional signals about the income distribution so far focuses on a scenario in which, at the beginning of the experiment, the individuals receive rather detailed information on the distribution of final portfolio values. An advantage of this setup is that the subjects start with a common prior and that learning dynamics become less important. This allows us to separate the effects of additional information on the beliefs about the distribution of incomes and about the own income. At the same time, however, the value of additional information is weakened when detailed information on the income distribution is available at the beginning of the experiment. In addition, the "information effect" may generally be different in situations in which individuals face a considerably higher degree of uncertainty.

In further control sessions, we vary the information that subjects receive on the income distribution. More precisely, while the experimental instructions of main treatments display a "cloud" of possible portfolio developments (compare the graph in Appendix C) from which the subjects can conclude on the income distribution, we do not provide this information in

\footnotetext{
${ }^{40}$ The coefficients of $P 2-I N F O$ and $\Delta_{y_{j, r}}(t)-y_{i, r}(t) \times P 2-I N F O$ are jointly marginally significant in specification 5 ( $p$-value is 0.103) and insignificant in specification 6 ( $p$-value 0.166). Note also that the effect of information at early points time (specification 5 of Table 3 ) is more sizable than the effect for the complete sample (specification 3 of Table 1) but less precisely estimated due to the smaller sample size.

${ }^{41}$ These findings on the dynamics are confirmed when using the indicator variable $I_{y_{j, r}(t)>y_{i, r}(t)}$ for being ahead or behind (and good or bad information, respectively) to identify treatment effects, just as in specification 2 of tables 1 and 2. As the only difference in terms of results obtained, the income-comparison effect (the treatment effect of P2-Income on satisfaction, as compared to P2-INFO) becomes stronger at later points in time. The latter may be caused by the fact that the indicator variable $I_{y_{j, r}(t)>y_{i, r}(t)}$ treats small and large inequalities in the same way, but observed income inequalities are larger at later points in time.
} 
the control sessions. Hence, for subjects in the control sessions the experimental instructions contain no information at all on the income-generating process or the probability distribution of final portfolio values. Apart from this change in the information on the income distribution provided to the subjects, the resulting treatments called BASE-C and P2-INFO-C ("control") follow the exact same rules as the original BASE and P2-INFO treatments and are based on the same set of portfolios. ${ }^{42}$ Therefore, "information effects" can be identified just as in the main analysis.

Before turning to the treatment comparisons of BASE-C and P2-INFO-C within the control sessions under increased uncertainty we briefly compare the subjects' stated beliefs in the control sessions to the data of the original sessions analyzed in the previous sections. For the very early observations (that is, the first points in time where beliefs are elicited) stated beliefs are less accurate in the control sessions than in the original sessions. This holds, however, only for the very early observations in the first round and is stronger in the BASE treatment (where subjects observe their own portfolio only) than in the P2-INFO treatment (where subjects also observe a second portfolio). ${ }^{43}$ Already from the end of the first round on and in all future rounds, the stated beliefs in BASE (P2-INFO) are very similar in the original and in the control sessions. Overall, the data suggests that at the beginning of the control sessions subjects underestimate the variance of the final income distribution but rather expect their income to take some average value. ${ }^{44}$ However, the subjects' beliefs seem to adjust very quickly toward the stated beliefs in the original sessions.

Taking this finding on learning dynamics into account we can estimate the "information effect" in the control sessions based on the same identification strategy as in Section 3.1. The estimation results are summarized in Table A.3 in Appendix A and are based on samples of observations from the treatments BASE-C and P2-INFO-C, contrasting the information effect in early rounds and at early points in time $t$ within a round to the effect in later rounds where the subjects have already received a number of signals on the income distribution. ${ }^{45}$

\footnotetext{
${ }^{42}$ For the experimental instructions in the control sessions we use the exact same instructions as in the original treatments, except that we remove the last paragraph including the figure that shows the "cloud" of possible portfolios (compare Appendix C). We run three sessions for the BASE-C treatment and four sessions for the P2-INFO-C treatment (168 subjects with 40 observations per subject in total).

${ }^{43}$ More precisely, for the first point in time where beliefs are elicited (where the uncertainty in the control sessions is likely to be most important), the correlation of the stated beliefs with the final portfolio value is only 0.26 in BASE-C (compared to 0.44 in the original BASE treatment). While this difference might already seem small, it becomes even smaller when comparing P2-INFO-C to P2-INFO (0.34 compared to 0.50), and it fades out the more observations from later rounds are included.

${ }^{44}$ In fact, in all sessions we observe that subjects, on average, underestimate the value of portfolios with a positive trend and overestimate the value of portfolios with a negative trend; this effect is, however, strongest in early observations of the control sessions with increased uncertainty.

${ }^{45}$ Note that we again exclude one subject (out of 168) whose beliefs are "implausible" in the sense that the responses were always below 10 points. Note also that due to unintentional heterogeneity in the composition
} 
When including only observations from the early rounds, the effects of additional information (the coefficients of P2-INFO and of the interaction term $\Delta_{y_{j, r}(t)-y_{i, r}(t)} \times P 2-I N F O$ jointly) are very imprecisely measured and are not significantly different to zero. In later rounds, however, the signs of the estimated coefficients change and the observed effects approach the results from the original sessions reported in Section 3.1: focusing on the effect of bad additional information and taking into account that the normalized difference $\Delta_{y_{j, r}(t)-y_{i, r}(t)}$ reaches a value -1 for the "worst" information observed we find a highly insignificant effect between -3.45 and 12.15 in rounds 1 and 2 (see specification 1 of Table A.3) that shifts, still insignificant, to an effect in the range between -4.05 and -0.98 in rounds 1 to 5 (see specification 2 of Table A.3). For rounds 6 to 10, the estimated effect of bad additional information is between -14.53 to -10.25 (see specification 2 of Table A.3; the coefficients of $P 2-I N F O$ and the interaction term $\Delta_{y_{j, r}(t)-y_{i, r}(t)} \times P 2-I N F O$ are jointly significant at the $10 \%$ level). In the latter case, the estimated effects in the control sessions are very similar to the results obtained for situations in which subjects are endowed with a rather exact common prior on the income distribution (compare, for instance, specification 3 of Table 1 and specification 5 of Table 3). ${ }^{46}$ Again, the information effect is driven by bad additional information and is insignificant in case of good additional information. ${ }^{47}$

Result 4 Under higher uncertainty over the income distribution we do not measure a significant effect of observing additional information in early rounds. In later rounds, subjects' beliefs are significantly lower when observing bad additional information $\left(y_{j}(t)<y_{i}(t)\right)$, while there is no significant effect on the subjects' beliefs when observing good additional information $\left(y_{j}(t)>y_{i}(t)\right)$.

The control sessions confirm the finding that subjects may react differently to "bad news" and to "good news," even in situations with higher uncertainty where much less information on the income distribution is available. For this asymmetric information effect

of the sessions the set of observations of the control sessions is not perfectly balanced in the sense that the number of subjects who observe the exact same portfolio is not exactly the same in BASE-C and in P2-INFOC. In the estimations we control for this issue with portfolio-specific random effects; moreover, estimations on subsamples which are perfectly balanced confirm the findings on the information effect discussed below.

${ }^{46}$ Using the entire sample of the additional control treatments (see in specification 4 of Table A.3), however, we do not measure a statistically significant effect of additional (good or bad) information, which is not surprising given the learning dynamics presented in specifications 1 to 3 .

${ }^{47}$ When identifying the treatment effect of additional information based on the indicator variable $I_{y_{j, r}(t)>y_{i, r}(t)}$ for good additional information (as in specification 2 of Table 1) we find very similar results: In early rounds there is no significant treatment effect of additional information (neither for good nor for bad information). In later rounds, however, we find the asymmetric effect that only bad additional information significantly (and negatively) affects stated beliefs. These results and estimations on separate subsamples for good and bad additional information applying the specifications in Table A.3 are available on request. 
to be measurable, it seems important that subjects have some idea of what the income distribution might look like. For early observations where subjects do not know anything about the income distribution, additional signals may have several and countervailing effects, affecting both the posterior about the income distribution as well as the expectation of the own income. ${ }^{48}$ While the learning dynamics are interesting per se, the results of the control sessions with higher uncertainty can also be seen as a robustness check of our main results.

\section{Conclusion}

Guided by Hirschman's idea of the "tunnel effect" we analyze direct income-comparison effects and indirect belief-based information effects when individuals observe signals on the income of others, in an environment characterized by uncertainty over the own income prospects. The empirical results of our experiment show that when individuals observe bad additional information (others are likely to earn less), they lower their beliefs about their own income. Observing good additional information (others are likely to earn more), however, does not have a statistically measurable effect on beliefs about the own income. Moreover, observing signals that indicate a lower expected income relative to others has a negative effect on individual well-being, while observing signals that indicate a higher expected income relative to others has no statistically measurable effect on individual wellbeing. Hence, we find asymmetric effects of information and of comparison considerations. For the combined "income-comparison effect" and "information effect" we find that under high uncertainty over final incomes both countervailing effects offset each other, statistically leading to a zero total effect. But as uncertainty decreases over time income-comparison effects dominate the informational effects such that individuals report significantly lower satisfaction when observing that others are ahead. Thus, our evidence suggests, in line with Hirschman's idea, that informational and comparison effects are simultaneously at work, with the dynamics playing a crucial role: the countervailing forces of informational effects are particularly relevant at early points in time, when additional information first arrives and uncertainty is still substantial. At a later stage, stable inequalities and a lower informational value of additional signals about others' experiences lead to a situation in which income-comparison considerations clearly prevail. Since we intentionally leave individuals

\footnotetext{
${ }^{48}$ As an illustration, suppose that subjects believe that the income distribution is concentrated around a value very close to the initial value $y(0)$ (that is, they underestimate the variance of portfolios). If a subject has a portfolio with a currently positive trend and observes a second portfolio with a negative trend, this may provide information on the variance of final incomes and may, hence, lead to higher beliefs about the own final portfolio value. Such an effect would counteract the negative effect of "bad news" observed in the original sessions where the variance of the income distribution is basically known due to the information provided in the instructions.
} 
uncertain of the informativeness of additional signals our findings on informational effects can be interpreted as rather strong and might be expected to dominate in environments in which the income-generating processes are clearly correlated.

Maybe surprisingly, we find asymmetric effects both for informational effects on the beliefs about the own income and for income-comparison effects. We interpret this finding as subjects being more reactive to "bad news" than to "good news." This offers interesting implications for attitudes toward redistribution and for the acceptance of income inequality. First, and maybe most straightforward to see, an asymmetric "income-comparison effect" implies that individuals experience a lower tolerance for inequality (ceteris paribus) and favor more redistribution. Catching up to richer individuals will be more important than the possible disutility resulting from other individuals catching up in terms of income relative to oneself. Consequently, redistributing from richer to poorer individuals compared to oneself would be perceived as favorable. Second, when signals of upside potentials in future income are less recognized, but signals of downside potentials lead to an updating of the own expectations, this will increase the support for redistributive policies. Raising taxes on high incomes will be seen less critically, as individuals are less sensitive to signals that indicate good income prospects for themselves. On the other hand, as individuals are sensitive to potentially bad signals about the own income prospects individuals will consider social assistance programs in support of low income levels as relatively more important, reinforcing Varian's (1980) argument of "redistributive taxation as social insurance." Therefore, the asymmetries in the information-based and in the direct income-comparison effects imply that individuals experience a lower tolerance for inequality and favor more redistribution.

\section{References}

[1] Alesina, A., and G.-M. Angeletos, 2005, Fairness and redistribution, American Economic Review, 95(4), 960-980.

[2] Alesina, A., Di Tella, R., and R. MacCulloch, 2004, Inequality and happiness: Are Europeans and Americans different?, Journal of Public Economics, 88(9), 2009-2042.

[3] Alesina, A., and E. La Ferrara, 2005, Preferences for redistribution in the land of opportunities, Journal of Public Economics, 89(5), 897-931.

[4] Balafoutas, L., Kerschbamer, R., and M. Sutter, 2012, Distributional preferences and competitive behavior, Journal of Economic Behavior and Organization, 83(1), 125-135. 
[5] Bénabou, R., and E.A. Ok, 2001, Social mobility and the demand for redistribution: The POUM hypothesis, Quarterly Journal of Economics, 116(2), 447-487.

[6] Bénabou, R., and J. Tirole, 2006, Belief in a just world and redistributive politics, Quarterly Journal of Economics, 121(2), 699-746.

[7] Beshears, J., Choi, J.J., Fuster, A., Laibson, D., and B.C. Madrian, 2013, What goes up must come down? Experimental evidence on intuitive forcasting, American Economic Review, 103(3), 570-574.

[8] Boskin, M.J., and E. Sheshinski, 1978, Optimal redistributive taxation when individuals welfare depends upon relative income, Quarterly Journal of Economics, 92(4), 589-601.

[9] Checchi, D., and A. Filippin, 2004, An experimental study of the POUM hypothesis, in Frank Cowell (ed.) Inequality, Welfare and Income Distribution: Experimental Approaches (Research on Economic Inequality, Volume 11) Emerald Group Publishing, $115-136$.

[10] Clark, A.E., Frijters, P., and M.A. Shields, 2008, Relative income, happiness, and utility: An explanation for the Easterlin paradox and other puzzles, Journal of Economic Literature, 46(1), 95-144.

[11] Clark, A.E., Kristensen, N., and N. Westergard-Nielsen, 2009, Job satisfaction and co-worker wages: Status or signal?, Economic Journal, 119(536), 430-447.

[12] Clark, A.E., and A.J. Oswald, 1996, Satisfaction and comparison income, Journal of Public Economics, 61(3), 359-381.

[13] Clark, A.E., and C. Senik, 2010, Who compares to whom? The anatomy of income comparisons in Europe, Economic Journal, 120(544), 573-594.

[14] Cojocaru, A., 2014, Prospects of upward mobility and preferences for redistribution: Evidence from the Life in Transition Survey, European Journal of Political Economy, $34,300-314$.

[15] Corneo, G., and H.P. Grüner, 2002, Individual preferences for political redistribution, Journal of Public Economics, 83(1), 83-107.

[16] Dohmen, T., Falk, A., Huffman, D., Sunde, U., Schupp, J., and G.G. Wagner, 2011, Individual risk attitudes: Measurement, determinants, and behavioral consequences, Journal of the European Economic Association, 9(3), 522-550. 
[17] Duesenberry, J.S., 1949, Income, saving and the theory of consumer behavior, Cambridge MA: Harvard University Press.

[18] Durante, R., Putterman, L., and J. van der Weele, 2014, Preferences for redistribution and perception of fairness: An experimental study, Journal of European Economic Association, 12(4), 1059-1086.

[19] Dwyer, G.P., Williams, A.W., Battalio, R.C., and T.I. Mason, 1993, Tests of rational expectations in a stark setting, Economic Journal, 103(418), 586-601.

[20] Easterlin, R.A., 1974, Does economic growth improve the human lot? Some empirical evidence, in (R. David and R. Reder, eds.), Nations and Households in Economic Growth: Essays in Honor of Moses Abramovitz, 89-125, New York: Academic Press.

[21] Easterlin, R.A., 1995, Will raising incomes of all increase the happiness of all? Journal of Economic Behavior and Organization, 27(1), 35-47.

[22] Fehr, E., and L. Goette, 2007, Do workers work more if wages are high? Evidence from a randomized field experiment, American Economic Review, 97(1), 298-317.

[23] Ferrer-i-Carbonell, A., 2005, Income and well-being: An empirical analysis of the comparison income effect, Journal of Public Economics, 89(5), 997-1019.

[24] Ferrer-i-Carbonell, A., and P. Frijters, 2004, How important is methodology for the estimates of the determinants of happiness?, Economic Journal, 114(497), 641-659.

[25] Ferrer-i-Carbonell, A., and X. Ramos, 2014, Inequality and happiness, Journal of Economic Surveys, 28(5), 1016-1027.

[26] Fischbacher, U., 2007, Z-tree: Zurich tool box for ready-made economic experiments, Experimental Economics, 10(2), 171-178.

[27] Fong, C., 2001, Social preferences, self-interest, and the demand for redistribution, Journal of Public Economics, 82(2), 225-246.

[28] Frank, R.H., 1984, Interdependent preferences and the competitive wage structure, Rand Journal of Economics, 15, 510-520.

[29] Frank, R.H., 1985, The demand for unobservable and other non-positional goods. American Economic Review, 75(1), 101-116.

[30] Frey, B.S., and A. Stutzer, 2002, What can economists learn from happiness research?, Journal of Economic Literature, 40(2), 402-435. 
[31] Guillaud, E., 2013, Preferences for redistribution: An empirical analysis over 33 countries, Journal of Economic Inequality, 11(1), 57-78.

[32] Greiner, B., 2004, An online recruitment system for economic experiments. in (K. Kremer and V. Macho, eds.), Forschung und wissenschaftliches Rechnen 2003. GWDG Bericht 63, 79-93, Göttingen: Ges. für Wiss. Datenverarbeitung.

[33] Hey, J.D., 1994, Expectations formation: Rational or adaptive or ...?, Journal of Economic Behavior and Organization, 25(3), 329-349.

[34] Hirschman, A., with Rothschild, M.,1973, The changing tolerance for income inequality in the course of economic development, Quarterly Journal of Economics, 87(4). 544-566.

[35] Hommes, C., 2011, The heterogeneous expectations hypothesis: Some evidence from the lab, Journal of Economic Dynamics and Control, 35(1), 1-24.

[36] Konrad, K.A., 1992, Wealth seeking reconsidered, Journal of Economic Behavior and Organization, 18(2), 215-227.

[37] Konrad, K.A., and F. Morath, 2013, Social mobility and redistributive taxation, CEPR Discussion Paper No. 7997.

[38] Konrad, K.A., and K.E. Lommerud, 1993, Relative standing comparisons, risk taking, and safety regulations, Journal of Public Economics, 51(3), 345-358.

[39] Krawczyk, M., 2010, A glimpse through the veil of ignorance: Equality of opportunity and support for redistribution, Journal of Public Economics, 94(1-2), 131-141.

[40] Leibenstein, H., 1950, Bandwagon, snob, and Veblen effects in the theory of consumers' demand, Quarterly Journal of Economics, 65(2), 183-207.

[41] Luttmer, E.F.P., 2005, Neighbors as negatives: Relative earnings and well-being, Quarterly Journal of Economics, 120(3), 963-1002.

[42] Luttmer, E.F.P., and M. Singhal, 2011, Culture, context, and the taste for redistribution, American Economic Journal: Economic Policy, 3(1), 157-179.

[43] McBride, M., 2001, Relative-income effect on subjective well-being in the cross-section, Journal of Economic Behaviour and Organization, 45(3), 251-278.

[44] Piketty, T., 1995, Social mobility and redistributive politics, Quarterly Journal of Economics, $110(3), 551-584$. 
[45] Putterman, L., 1997, Why have the rabble not redistributed the wealth? On the stability of democracy and unequal property, in (J.E. Roemer, ed.), Property relations, incentives and welfare, Palgrave Macmillan UK, 359-393.

[46] Ravallion, M., and M. Lokshin, 2000, Who wants to redistribute? The tunnel effect in 1990s Russia, Journal of Public Economics, 76(1), 87-104.

[47] Rötheli, T.F., 2011, Pattern-based expectations: International experimental evidence and applications in financial economics, Review of Economics and Statistics, 93(4), 1319-1330.

[48] Schmalensee, R., 1976, An experimental study of expectation formation, Econometrica, $44(1), 17-41$.

[49] Senik, C., 2004, When information dominates comparison. Learning from Russian subjective panel data, Journal of Public Economics, 88(9), 2099-2123.

[50] Senik, C., 2008, Ambition and jealousy: Income interaction in the 'old' Europe versus the 'new' Europe and the United States, Economica, 75(299), 495-513.

[51] Senik, C., 2009, Direct evidence on income comparisons and their welfare effects, Journal of Economic Behavior and Organization, 72(1), 408-424.

[52] van de Stadt, H., Kapteyn, A., and S. van de Geer, 1985, The relativity of utility: Evidence from panel data, Review of Economics and Statistics, 67(2), 179-187.

[53] Varian, H.R., 1980, Redistributive taxation as social insurance, Journal of Public Economics, 14(1), 49-68.

[54] Veblen, T., 1899, The theory of the leisure class (reprinted 1953, Mentor Books, New York).

[55] Weimann, J., Knabe, A., and R. Schöb, 2015, Measuring happiness: The economics of well-being, MIT Press. 


\section{A Appendix}

\section{A.1 Experimental treatments}

\begin{tabular}{lccccc}
\hline \hline Treatments & BASE & P2-INFO & P2-INCOME & BASE-C & P2-INFO-C \\
\hline \# sessions & 4 & 4 & 4 & 3 & 4 \\
\# participants & 96 & 96 & 96 & 72 & 96 \\
\# observations & & 40 & 40 & 40 & 40 \\
per participant & 40 & 40 & & & \\
\hline \hline
\end{tabular}

Note: In BASE, subjects only observe their own portfolio; in P2-INFO, subjects observe their own portfolio and an additional portfolio which is not payoff-relevant for any participant; in P2-INCOME, subjects observe their own portfolio and the portfolio of another participant. The control treatments BASE-C and P2-INFO$\mathrm{C}$ are identical to the treatments BASE and P2-INFO, except subjects do not receive information on the distribution of final portfolio values (see Section 3.4).

Table A.1: Summary of the experimental treatments.

\section{A.2 Descriptive statistics}

\begin{tabular}{lccccccc}
\hline \hline & BASE & P2-INFO & P2-INCOME & \multicolumn{4}{c}{ Total } \\
\cline { 5 - 8 } & Mean & Mean & Mean & Mean & S.D. & Max & Min \\
\hline Male & 0.47 & 0.37 & 0.34 & 0.39 & 0.49 & 1 & 0 \\
Age & 23.8 & 22.8 & 22.8 & 23.1 & 4.2 & 52 & 17 \\
Econ & 0.33 & 0.29 & 0.40 & 0.34 & 0.47 & 1 & 0 \\
\hline Belief & 309.2 & 306.4 & 308.9 & 308.2 & 101.5 & 902 & 0 \\
Bad Add. Info. & 359.4 & 354.1 & 359.3 & 357.6 & 85.5 & 902 & 0 \\
Good Add. Info. & 258.9 & 258.7 & 258.6 & 258.7 & 91.7 & 750 & 1 \\
\hline Satisfaction & 4.57 & 4.49 & 4.39 & 4.49 & 2.69 & 10 & 0 \\
Behind & 3.37 & 3.25 & 3.02 & 3.21 & 2.32 & 10 & 0 \\
Ahead & 5.78 & 5.73 & 5.75 & 5.76 & 2.42 & 10 & 0 \\
\hline \hline
\end{tabular}

Note: "Male" takes a value of 1 for male subjects. "Econ" takes a value of 1 for subjects that study in business-related fields such as economics. "Bad Add. Info." refers to situations when subjects observe an additional portfolio of a lower value than their own portfolio (bad additional information). "Good Add. Info." refers to situations when subjects observe an additional portfolio of a higher value than their own portfolio (good additional information). "Behind" refers to the case of being behind in relative-income. "Ahead" refers to situations of being ahead in relative-income.

Table A.2: Summary statistics for the main treatments. 


\section{A.3 Histograms of stated beliefs and satisfaction levels}
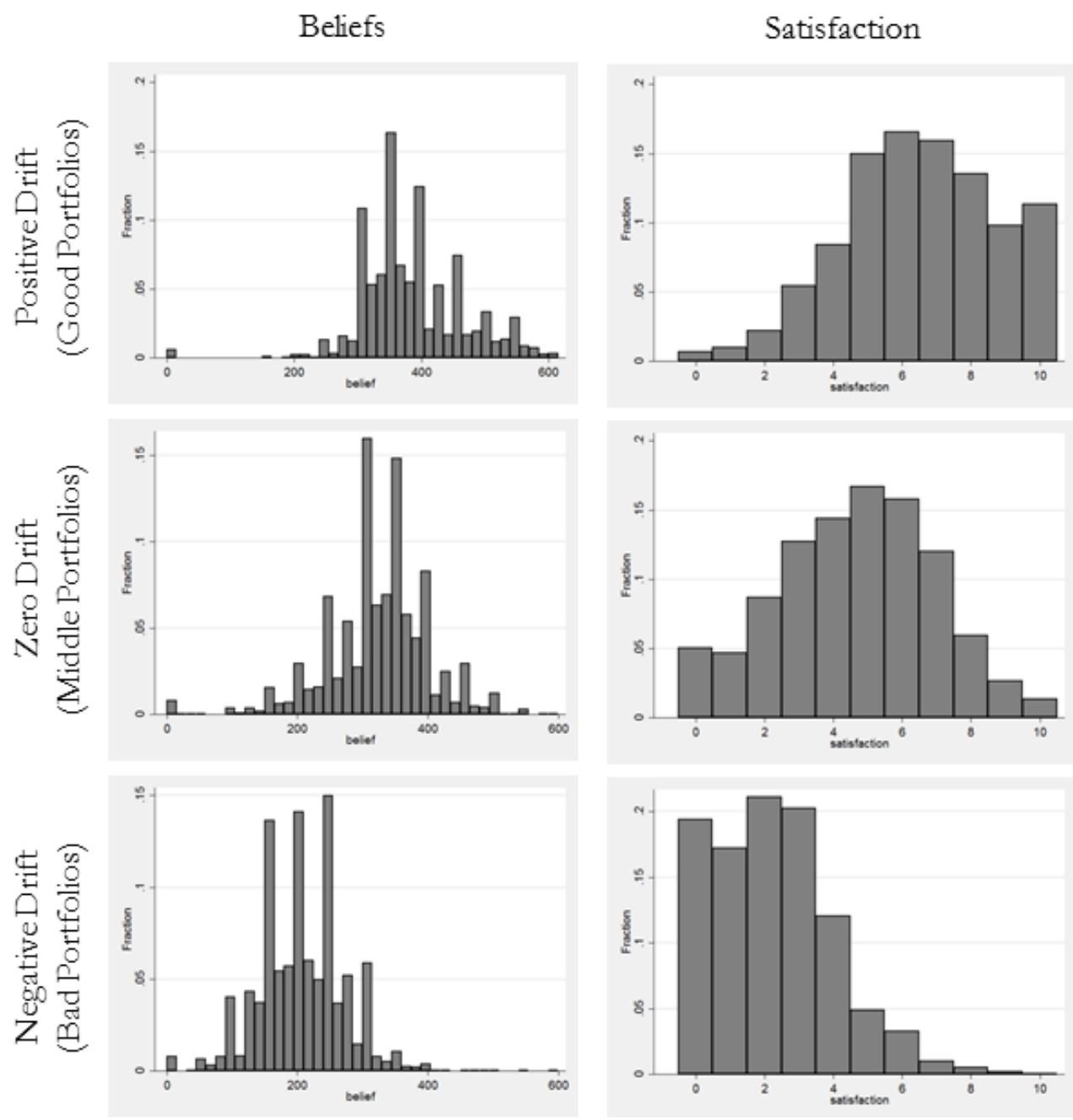

Figure A.1: Distributions of measured beliefs and satisfaction for different portfolio types (with positive, zero and negative drift of the stochastic portfolio-generating process). 


\section{A.4 Screenshot of the experimental task}

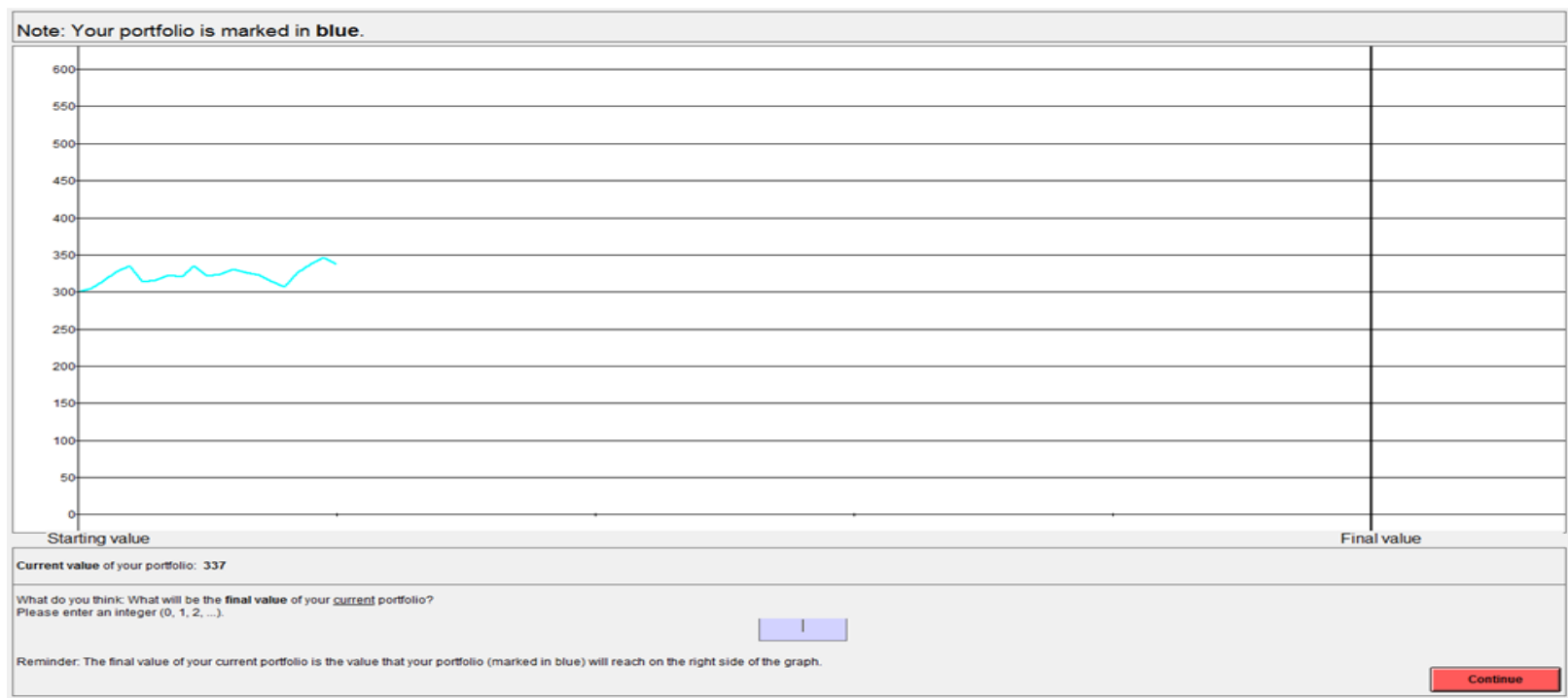

Figure A.2: Screenshot of the experiment (for the question on beliefs in the BASE treatment). 


\section{A.5 Estimation results for the sessions with increased uncertainty}

\begin{tabular}{|c|c|c|c|c|}
\hline & Round 1 to 2 & Round 1 to 5 & Round 6 to 10 & Round 1 to 10 \\
\hline & $\begin{array}{c}\text { Early } t \\
(1) \\
\text { belief }\end{array}$ & $\begin{array}{c}\text { Early } t \\
(2) \\
\text { belief }\end{array}$ & $\begin{array}{c}\text { Early } t \\
(3) \\
\text { belief }\end{array}$ & $\begin{array}{c}\text { All } t \\
(4) \\
\text { belief }\end{array}$ \\
\hline$y_{i, r}(t)$ & $\begin{array}{c}0.867^{* * *} \\
(0.071)\end{array}$ & $\begin{array}{c}0.861^{* * *} \\
(0.039)\end{array}$ & $\begin{array}{c}1.009^{* * *} \\
(0.038)\end{array}$ & $\begin{array}{c}0.871^{* * *} \\
(0.017)\end{array}$ \\
\hline P2-INFO & $\begin{array}{l}-3.450 \\
(17.64)\end{array}$ & $\begin{array}{r}-4.049 \\
(11.07)\end{array}$ & $\begin{array}{c}-12.39^{* *} \\
(5.819)\end{array}$ & $\begin{array}{c}-5.758 \\
(5.809)\end{array}$ \\
\hline$\Delta_{y_{j, r}(t)-y_{i, r}(t)}$ & $\begin{array}{l}-10.41 \\
(12.30)\end{array}$ & $\begin{array}{c}-22.83^{* * *} \\
(7.430)\end{array}$ & $\begin{array}{c}-0.448 \\
(6.334)\end{array}$ & $\begin{array}{r}-1.277 \\
(3.076)\end{array}$ \\
\hline $\begin{array}{r}\Delta_{y_{j, r}(t)-y_{i, r}}(t) \\
\quad \times \mathrm{P} 2-\mathrm{INFO}\end{array}$ & $\begin{array}{l}-15.60 \\
(12.97)\end{array}$ & $\begin{array}{c}-3.072 \\
(7.954)\end{array}$ & $\begin{array}{l}2.140 \\
(4.584)\end{array}$ & $\begin{array}{l}-3.156 \\
(2.230)\end{array}$ \\
\hline Constant & $\begin{array}{l}54.45 \\
(42.39)\end{array}$ & $\begin{array}{c}66.44^{* * *} \\
(25.60)\end{array}$ & $\begin{array}{l}0.599 \\
(16.88)\end{array}$ & $\begin{array}{c}55.31^{* * *} \\
(13.09)\end{array}$ \\
\hline $\begin{array}{l}\text { Individual controls } \\
\text { Time and session fixed effects }\end{array}$ & $\begin{array}{l}\text { Yes } \\
\text { Yes }\end{array}$ & $\begin{array}{l}\text { Yes } \\
\text { Yes }\end{array}$ & $\begin{array}{l}\text { Yes } \\
\text { Yes }\end{array}$ & $\begin{array}{l}\text { Yes } \\
\text { Yes }\end{array}$ \\
\hline$N$ & 668 & 1670 & 1670 & 6680 \\
\hline
\end{tabular}

Note: Crossed-effects regression model with random effects on subject and portfolio level. Dependent variables: beliefs. Standard errors in parentheses, ${ }^{*} \mathrm{p}<0.10,{ }^{* *} \mathrm{p}<0.05,{ }^{* * *} \mathrm{p}<0.01$. "Individual controls" include gender, age, whether the field of study is business related, risk aversion, loss aversion, ambiguity aversion, distributional preferences, optimism and patience. "Time and session fixed effects" include round fixed effects, point-in-time fixed effects, fixed effects for the sequence in which the selected portfolios are shown, and session fixed effects.

Table A.3: Information effect under increased uncertainty: Regression results. 


\section{B Supplementary material}

\section{B.1 Income-comparison effect for the two variants of the control question}

\begin{tabular}{lccc}
\hline \hline & CQ & CQH & Pooled \\
& $(1)$ & $(2)$ & $(3)$ \\
& satisfaction & satisfaction & satisfaction \\
\hline$y_{i, r}(t)$ & $0.016^{* * *}$ & $0.018^{* * *}$ & $0.017^{* * *}$ \\
& $(0.001)$ & $(0.001)$ & $(0.001)$ \\
belie $f_{i, r}(t)$ & $0.005^{* * *}$ & $0.003^{* * *}$ & $0.004^{* * *}$ \\
P2-INCOME & $(0.001)$ & $(0.001)$ & $(0.000)$ \\
& -0.077 & -0.175 & -0.207 \\
$I_{y_{j, r}(t)>y_{i, r}(t)}$ & $(0.260)$ & $(0.246)$ & $(0.247)$ \\
& $-0.889^{* * *}$ & $-0.780^{* * *}$ & $-0.862^{* * *}$ \\
P2-INCOME $\times I_{y_{j, r}(t)>y_{i, r}(t)}$ & $(0.088)$ & $(0.097)$ & $(0.065)$ \\
Constant & $-0.221^{* * *}$ & $-0.256^{* * *}$ & $-0.236^{* * *}$ \\
& $(0.087)$ & $(0.098)$ & $(0.065)$ \\
\hline Individual controls & $-0.825^{* * *}$ & $-0.808^{* * *}$ & $-1.254^{* * *}$ \\
Time and session fixed effects & $(0.350)$ & $(0.343)$ & $(0.281)$ \\
\hline$N$ & Yes & Yes & Yes \\
\hline \hline
\end{tabular}

Note: Crossed-effects regression model with random effects on subject and portfolio level. Observations from treatments P2-INFO and P2-INCOME. Dependent variable: satisfaction. Standard errors in parentheses, ${ }^{*} \mathrm{p}<0.10,{ }^{* *} \mathrm{p}<0.05,{ }^{* * *} \mathrm{p}<0.01$. The sample of observations depends on the variant of the control question. In "CQ" the subjects were given the choice of having their earnings determined by the final value of another, randomly drawn portfolio; in "CQH" this control question was only asked "hypothetically" and was not actually implemented. "Pooled" refers to the full sample based on both variants of the control question. "Individual controls" include gender, age, whether the field of study is business-related, risk aversion, loss aversion, ambiguity aversion, distributional preferences, optimism, and patience. "Time and session fixed effects" include round fixed effects, point-in-time fixed effects, fixed effects for the sequence in which the selected portfolios are shown, and session fixed effects.

Table B.1: Income-comparison effect: Separate regression results depending on the variant of the control question used in the experiment. 


\section{B.2 Information effect: Additional estimation results}

\begin{tabular}{|c|c|c|}
\hline & $\begin{array}{c}(1) \\
\text { belief }\end{array}$ & $\begin{array}{c}(2) \\
\text { belief }\end{array}$ \\
\hline$y_{i, r}(t)$ & $\begin{array}{c}0.841^{* * *} \\
(0.013)\end{array}$ & $\begin{array}{c}0.841^{* * *} \\
(0.013)\end{array}$ \\
\hline$P 2-I N F O$ & $\begin{array}{c}-13.02^{* *} \\
(5.936)\end{array}$ & $\begin{array}{c}-11.83^{*} \\
(6.160)\end{array}$ \\
\hline$Q 2_{y_{j, r}(t)-y_{i, r}(t)}$ & $\begin{array}{l}-1.090 \\
(2.691)\end{array}$ & $\begin{array}{l}-1.098 \\
(2.691)\end{array}$ \\
\hline$Q 3_{y_{j, r}(t)-y_{i, r}(t)}$ & $\begin{array}{c}-8.497^{* * *} \\
(3.173)\end{array}$ & $\begin{array}{c}-8.495^{* * *} \\
(3.173)\end{array}$ \\
\hline$Q 4_{y_{j, r}(t)-y_{i, r}(t)}$ & $\begin{array}{c}-13.28^{* * *} \\
(3.546)\end{array}$ & $\begin{array}{c}-13.29^{* * *} \\
(3.546)\end{array}$ \\
\hline$Q 2_{y_{j, r}(t)-y_{i, r}(t)} \times P 2-I N F O$ & $\begin{array}{c}2.033 \\
(2.980)\end{array}$ & $\begin{array}{c}2.63 \\
(2.980)\end{array}$ \\
\hline$Q 3_{y_{j, r}(t)-y_{i, r}(t)} \times P 2-I N F O$ & $\begin{array}{c}6.006^{* *} \\
(2.947)\end{array}$ & $\begin{array}{c}6.007^{* *} \\
(2.947)\end{array}$ \\
\hline$Q 4_{y_{j, r}(t)-y_{i, r}(t)} \times P 2-I N F O$ & $\begin{array}{c}6.044^{* *} \\
(3.033)\end{array}$ & $\begin{array}{c}6.077^{* *} \\
(3.033)\end{array}$ \\
\hline Constant & $\begin{array}{c}86.15^{* * *} \\
(8.000)\end{array}$ & $\begin{array}{c}86.76^{* * *} \\
(8.051)\end{array}$ \\
\hline Individual controls & No & Yes \\
\hline Time and session fixed effects & Yes & Yes \\
\hline$N$ & 7600 & 7600 \\
\hline
\end{tabular}

Note: Crossed-effects regression model with random effects on subject and portfolio level. Observations from treatments BASE and P2-INFO. Dependent variable: beliefs. Standard errors in parentheses, ${ }^{*} \mathrm{p}<0.10$, ${ }^{* *} \mathrm{p}<0.05,{ }^{* * *} \mathrm{p}<0.01$. The variables $\mathrm{Q} y_{y_{j, r}(t)-y_{i, r}(t)}$ to $\mathrm{Q} 4_{y_{j, r}(t)-y_{i, r}(t)}$ are indicator variables for quartiles of the difference $y_{j, r}(t)-y_{i, r}(t)$ at a given point in time $t$; Q2 $y_{j, r}(t)-y_{i, r}(t) \times \mathrm{P} 2$-INFO to $\mathrm{Q}_{y_{j, r}(t)-y_{i, r}(t)} \times \mathrm{P} 2-$ INFO are the respective interaction terms with the treatment dummy P2-INFO. Baseline category is Q1 $y_{j, r}(t)-y_{i, r}(t)$. Specification 2 adds "Individual controls": gender, age, whether the field of study is business-related, risk aversion, loss aversion, ambiguity aversion, distributional preferences, optimism and patience. "Time and session fixed effects" include round fixed effects, point-in-time fixed effects, fixed effects for the sequence in which the selected portfolios are shown, and session fixed effects.

Table B.2: Information effect: Regression results of disaggregated interaction model. 


\begin{tabular}{ccc}
\hline \hline Additional information & $\begin{array}{c}\text { Effect } \\
(\mathrm{p} \text {-value })\end{array}$ & Tested hypothesis \\
\hline Very Bad & $-13.02^{* *}$ & $H_{0}: \mathrm{P} 2$-INFO $=0$ \\
$\left(y_{j, r}(t)<<y_{i, r}(t)\right)$ & $(0.028)$ & \\
Bad & -10.987 & $H_{0}: \mathrm{P} 2-\mathrm{INFO}+Q 2_{y_{j, r}(t)-y_{i, r}(t)} \times \mathrm{P} 2-\mathrm{INFO}=0$ \\
$\left(y_{j, r}(t)<y_{i, r}(t)\right)$ & $(0.063)$ & \\
Good & -7.014 & $H_{0}: \mathrm{P} 2-\mathrm{INFO}+Q 3_{y_{j, r}(t)-y_{i, r}(t)} \times \mathrm{P} 2-\mathrm{INFO}=0$ \\
$\left(y_{j, r}(t)>y_{i, r}(t)\right)$ & $(0.239)$ & \\
Very Good & -6.976 & $H_{0}: \mathrm{P} 2-\mathrm{INFO}+Q 4_{y_{j, r}(t)-y_{i, r}(t)} \times \mathrm{P} 2-\mathrm{INFO}=0$ \\
$\left(y_{j, r}(t)>>y_{i, r}(t)\right)$ & $(0.240)$ & \\
\hline \hline
\end{tabular}

Note: The effect of additional information as estimated in specification 1 of Table B.2. ${ }^{*} \mathrm{p}<0.10,{ }^{* *} \mathrm{p}<0.05$, ${ }^{* * *} \mathrm{p}<0.01$. For the baseline category $\left(\mathrm{Q} 1_{y_{j, r}(t)-y_{i, r}(t)}\right)$, the treatment effect of additional information is given by the coefficient of P2-INFO. For the remaining quartiles, the treatment effect of additional information is given by the sum of the coefficients of P2-INFO and its interaction term with the indicator variable for the respective quartile (in the table, P2-INFO and Q2 $y_{j, r}(t)-y_{i, r}(t) \times \mathrm{P} 2$-INFO to $\mathrm{Q} 4_{y_{j, r}(t)-y_{i, r}(t)} \times \mathrm{P} 2$-INFO refer to the coefficients of the variables as estimated in specification 1 of Table B.2).

Table B.3: Disaggregated information effect: Hypothesis tests for good and bad additional information. 


\section{B.3 Income-comparison effect: Additional estimation results}

\begin{tabular}{lcc}
\hline \hline & $(1)$ & $(2)$ \\
& satisfaction & satisfaction \\
\hline$y_{i, r}(t)$ & $0.016^{* * *}$ & $0.016^{* * *}$ \\
& $(0.001)$ & $(0.001)$ \\
belie $f_{i, r}(t)$ & $0.004^{* * *}$ & $0.004^{* * *}$ \\
P2-INCOME & $(0.000)$ & $(0.000)$ \\
& -0.170 & -0.196 \\
$Q 2_{y_{j, r}(t)-y_{i, r}(t)}$ & $(0.260)$ & $(0.252)$ \\
$Q 3_{y_{j, r}(t)-y_{i, r}(t)}$ & $-0.367^{* * *}$ & $-0.366^{* * *}$ \\
$Q 4_{y_{j, r}(t)-y_{i, r}(t)}$ & $(0.084)$ & $(0.084)$ \\
$Q 2_{y_{j, r}(t)-y_{i, r}(t)} \times$ P2-INCOME & $-1.344^{* * *}$ & $-1.343^{* * *}$ \\
$Q 3_{y_{j, r}(t)-y_{i, r}(t)} \times$ P2-INCOME & $(0.100)$ & $(0.100)$ \\
$Q 4_{y_{j, r}(t)-y_{i, r}(t)} \times$ P2-INCOME & $-1.622^{* * *}$ & $-1.620^{* * *}$ \\
Constant & $(0.111)$ & $(0.111)$ \\
\hline Individual controls & 0.000 & -0.002 \\
Time and session fixed effects & $(0.093)$ & $(0.093)$ \\
\hline$N$ & $-0.161^{*}$ & $-0.161^{*}$ \\
\hline \hline
\end{tabular}

Note: Crossed-effects regression model with random effects on subject and portfolio level. Observations from treatments P2-INFO and P2-INCOME. Dependent variable: satisfaction. Standard errors in parentheses, ${ }^{*} \mathrm{p}<0.10,{ }^{* *} \mathrm{p}<0.05,{ }^{* * *} \mathrm{p}<0.01$. The variables $\mathrm{Q} 2_{y_{j, r}(t)-y_{i, r}(t)}$ to $\mathrm{Q} 4_{y_{j, r}(t)-y_{i, r}(t)}$ are indicator variables for quartiles of the difference $y_{j, r}(t)-y_{i, r}(t)$ at a given point in time $t$; $2_{y_{j, r}(t)-y_{i, r}(t)} \times \mathrm{P} 2$-INCOME to $\mathrm{Q} 4_{y_{j, r}(t)-y_{i, r}(t)} \times \mathrm{P} 2$-INCOME are the respective interaction terms with the treatment dummy P2-INCOME.

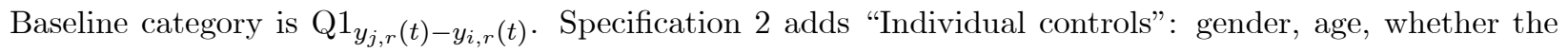
field of study is business-related, risk aversion, loss aversion, ambiguity aversion, distributional preferences, optimism, and patience. "Time and session fixed effects" include round fixed effects, point-in-time fixed effects, fixed effects for the sequence in which the selected portfolios are shown, and session fixed effects.

Table B.4: Income-comparison effect: Regression results of the disaggregated interaction model. 


\begin{tabular}{ccc}
\hline \hline Income-comparison & $\begin{array}{c}\text { Effect } \\
(\mathrm{p} \text {-value })\end{array}$ & Tested hypothesis \\
\hline Far ahead & -0.170 & $H_{0}:$ P2-INCOME $=0$ \\
$\left(y_{j, r}(t)<<y_{i, r}(t)\right)$ & $(0.512)$ & \\
Ahead & -0.170 & $H_{0}: \mathrm{P} 2$-INCOME $+Q 2_{y_{j, r}(t)-y_{i, r}(t)} \times \mathrm{P} 2-\mathrm{INCOME}=0$ \\
$\left(y_{j, r}(t)<y_{i, r}(t)\right)$ & $(0.511)$ & \\
Behind & -0.331 & $H_{0}: \mathrm{P} 2$-INCOME $+Q 3_{y_{j, r}(t)-y_{i, r}(t)} \times \mathrm{P} 2$-INCOME $=0$ \\
$\left(y_{j, r}(t)>y_{i, r}(t)\right)$ & $(0.203)$ & \\
Far behind & $-0.515^{* *}$ & $H_{0}: \mathrm{P} 2-\mathrm{INCOME}+Q 4_{y_{j, r}(t)-y_{i, r}(t)} \times \mathrm{P} 2-\mathrm{INCOME}=0$ \\
$\left(y_{j, r}(t)>>y_{i, r}(t)\right)$ & $(0.048)$ & \\
\hline \hline
\end{tabular}

Note: The effect of observing another participant's portfolio as estimated in specification (1) of Table B.4. ${ }^{*} \mathrm{p}<0.10,{ }^{* *} \mathrm{p}<0.05,{ }^{* * *} \mathrm{p}<0.01$. For the baseline category $\left(\mathrm{Q} 1_{y_{j, r}(t)-y_{i, r}(t)}\right)$, the treatment effect of observing another participant's portfolio is given by the coefficient of P2-INCOME. For the remaining quartiles, the treatment effect of observing another participant's portfolio is given by the sum of the coefficients of P2INCOME and its interaction term with the indicator variable for the respective quartile (in the table, P2-INCOME and $\mathrm{Q} 2 y_{j, r}(t)-y_{i, r}(t) \times \mathrm{P} 2$-INFO to $\mathrm{Q} 4_{y_{j, r}(t)-y_{i, r}(t)} \times \mathrm{P} 2$-INCOME refer to the coefficients of the variables as estimated in specification (1) of Table B.4).

Table B.5: Disaggregated income-comparison effect: Hypothesis tests for being behind and being ahead. 
B.4 Set of portfolios assigned in the experiment
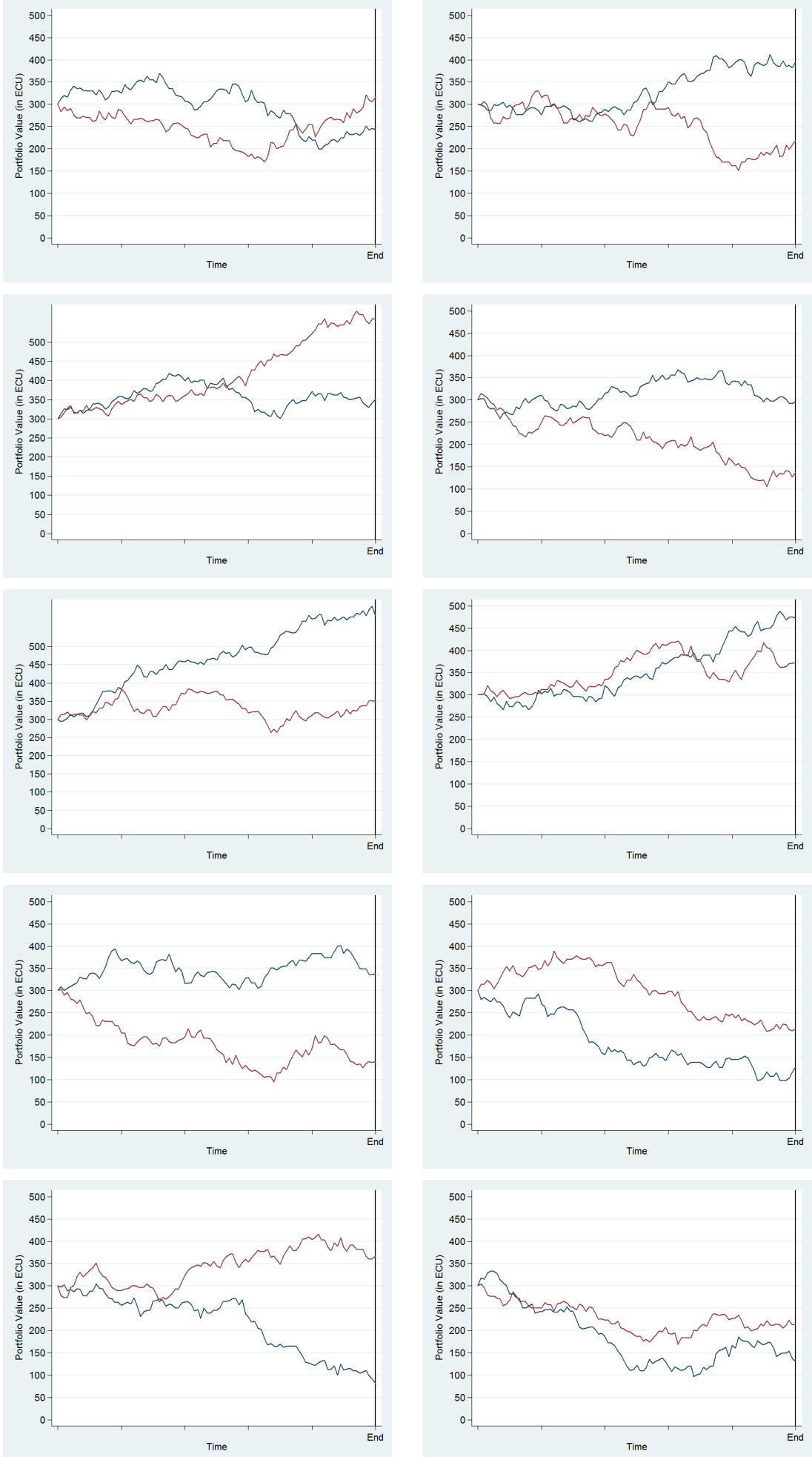

B. 6 


\section{Experimental instructions*}

Welcome to the Experiment! Please read these instructions carefully and completely. Thoroughly understanding the instructions will help you to earn more money.

Your earnings in the experiment are measured in Talers. At the end of the experiment we will convert the Talers you earned into Euros and pay you accordingly. The conversion rate is: 25 Talers $=1$ Euro. In addition, each participant will receive a show-up fee of 4 Euros.

We assure you of anonymity throughout the experiment. Please keep in mind that you are not allowed to communicate with other participants during the experiment. If you do not obey this rule you will be asked to leave the laboratory and will forfeit any payment. Whenever you have a question, please raise your hand and we will help you.

Your Task: In the experiment, each participant is assigned a portfolio whose current value you will observe in a graph on your screen. You can think of your "portfolio" as a part of the earnings you will receive at the end of the experiment. Portfolios are generated by the computer according to a random process. A graph at the end of these instructions illustrates possible portfolio processes.

You will be randomly assigned into groups of two. However, you will not know which of the other participants is assigned to you as your co-player. Each participant will observe the current value of the own portfolio and of the co-player's portfolio over time. The starting value of all portfolios is 300 Talers and the final portfolio value (a whole number larger than zero) represents the major part of your earnings of the experiment.

The dynamic change in portfolio values will stop at regular intervals and you will be asked the following questions on your screen:

1. How satisfied are you with your current portfolio on a scale from 0 (highly dissatisfied) to 10 (highly satisfied)?

2. What do you think: what will be the final value of your current portfolio (in Talers)?

3. Please choose one of the following two options:

(a) I prefer to be paid the final value of my current portfolio.

(b) I prefer to be paid the final value of a new portfolio, which is randomly generated and assigned to me at the end of the experiment.

You and your co-player will answer repeatedly and independently the same three questions. At each point in time you can choose your answers anew and fully independently of your previous answers. Your answers will not be displayed to your co-player.

${ }^{*}$ The experiment was conducted in German. This appendix contains a translated version of the instructions for the P2-InCome treatment. 
Until the final portfolio value has been reached you and your co-player will keep the assigned portfolios and will each answer the three questions with respect to the current portfolio. This also applies in case your answer to question three is to receive as a payment the final value of a new, randomly assigned portfolio.

Procedure: Overall, you will repeat this task 10 times. Consequently, you will observe 10 such portfolio processes. These 10 rounds are completely independent of each other: In each round the participants will be randomly re-matched in groups of two and each time you and your new co-player will each be randomly and independently assigned a new portfolio.

At the end of the experiment, in a first step, the computer will randomly select one of the 10 rounds. For the selected round the computer will select exactly one point in time at which you answered the three questions described above. Your payment will be determined by your answers at this selected point in time and will include three components:

- For your answer with respect to your satisfaction you will receive 50 Talers, independent of the value you entered.

- The better your estimate of the final portfolio value at the selected point in time matches the actual final portfolio value in the selected round, the more money you will receive:

- If you predicted precisely the realized final portfolio value, you will receive 250 Talers.

- The exact formula to calculate your payment is:

Payment $($ in Talers $)=250-\frac{1}{10}(\text { estimate }- \text { actual final value })^{2}$; at least, however, 25 Talers.

- You will receive the final value of your portfolio as a payment:

- If you chose Option 3(a) at the selected point in time, you will receive the final value of the portfolio assigned in the selected round.

- If you chose Option 3(b) at the selected point in time, a new portfolio will be randomly assigned to you and you will receive the final value of this new portfolio as a payment.

- Note: Should you receive the final value of a new, randomly selected portfolio, the complete portfolio process of this portfolio will be displayed on your screen at the end of the experiment.

In total, your payment will consist of the final portfolio value (in Talers), of the Talers earned when predicting the final portfolio value, and of the Talers you received for your answers with respect to your satisfaction. These Talers will be converted into Euros and paid to you in cash. After the experiment we will ask you to provide some more information; as a matter of course, all of your provided information will only be used anonymously.

Thank you very much for showing up, and good luck! 
The following graph illustrates possible portfolio realizations. The starting value of all portfolios is 300 Talers. On the horizontal axis the points in time are indicated (four in total) when you will be asked to answer the three questions explained above.

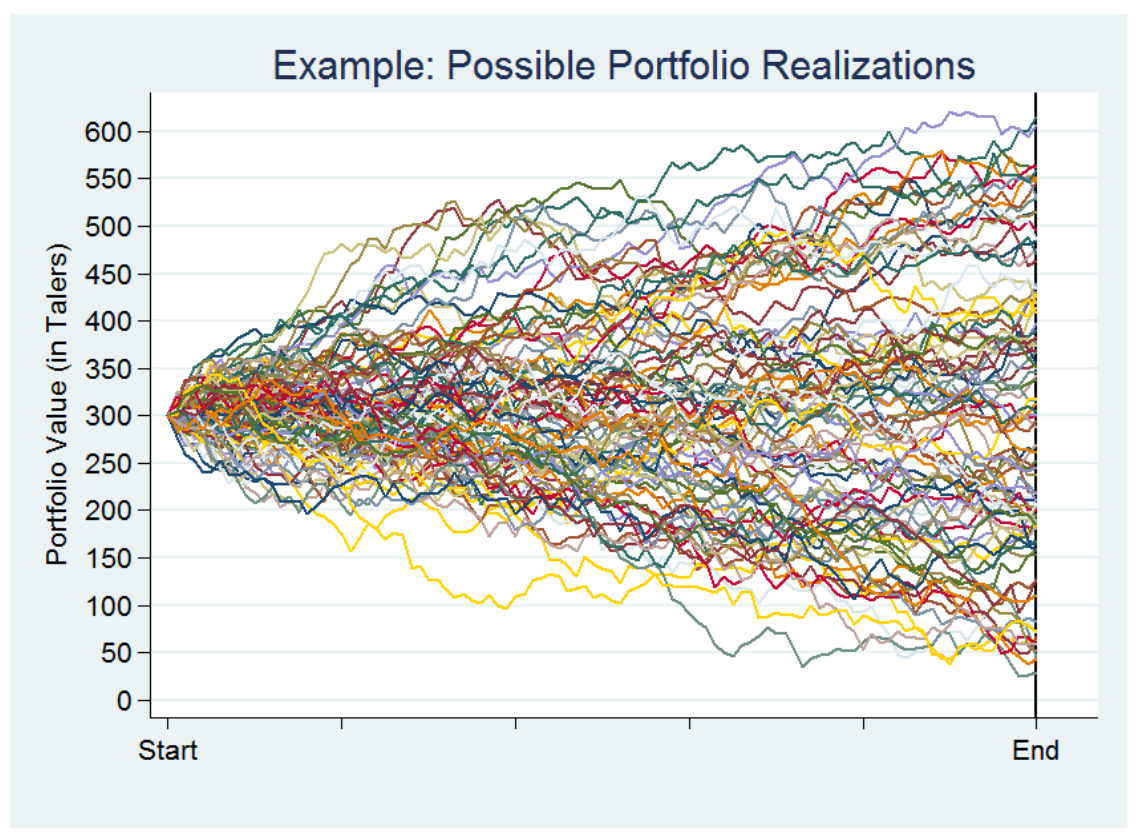

